\title{
Did CDS Trading Improve the Market for Corporate Bonds? ${ }^{1}$
}

\author{
Sanjiv Das \\ Santa Clara University
}

\author{
Madhu Kalimipalli \\ Wilfrid Laurier University
}

\author{
Subhankar Nayak \\ Wilfrid Laurier University
}

October 4, 2012

\begin{abstract}
${ }^{1}$ Das is at the Leavey School of Business, Santa Clara University, and can be reached at (408)554-2776 or srdas@scu.edu. Kalimipalli and Nayak are both affiliated with the School of Business \& Economics, Wilfrid Laurier University, Waterloo, Canada, N2L 3C5. Kalimipalli can be reached at (519)-884-0710 (ext: 2187) or mkalimipalli@wlu.ca. Nayak can be contacted at (519)-8840710 (ext: 2206) or snayak@wlu.ca. Kalimipalli acknowledges support from the Social Sciences and Humanities Research Council of Canada. The authors thank Melanie Cao, George Chacko, Paul Hanouna, Edith Hotchkiss, Allan Huang, Ravi Jagannathan, Ranjini Jha, Mark Kamstra, Nikunj Kapadia, Seoyoung Kim, Blake Phillips, Gordon Roberts, Yisong Tian, Heather Tookes, Bruce Tuckman, Ken Vetzal, Jason Wie, Rohan Williamson, Xing Zhou, and seminar participants at University of Waterloo, York University, Villanova-MARC conference (2011), FDIC-JFSR conference (2011), FMA Applied Conference (2011), FIRS Conference (2012), and WFA conference (2012) for helpful suggestions and discussions.
\end{abstract}




\section{Abstract \\ Did CDS Trading Improve the Market for Corporate Bonds?}

Financial innovation through the creation of new markets and securities impacts related markets as well, changing their efficiency, quality (pricing error) and liquidity. The credit default swap (CDS) market was undoubtedly one of the salient new markets of the past decade. In this paper we examine whether the advent of CDS trading was beneficial to the underlying secondary market for corporate bonds. We employ econometric specifications that account for information across CDS, bond, equity, and volatility markets. We also develop a novel methodology to utilize all observations in our data set even when continuous daily trading is not evidenced, because bonds trade much less frequently than equities. Using an extensive sample of CDS and bond trades over 2002-2008, we find that the advent of CDS was largely detrimental - bond markets became less efficient, evidenced no reduction in pricing errors, and experienced no improvement in liquidity. These findings are robust to various slices of the data set and specification of our tests.

Key words: CDS, bond market efficiency.

JEL classification: G10, G14 
"...We need broad regulatory reform of over-the-counter derivatives to best lower risk and promote transparency in the marketplace..."

CFTC Chairman Gary Gensler,

OTC Derivatives Reform Conference (Mar 9, 2010)

\section{Introduction}

Innovation is a double-edged sword and can have positive and negative outcomes. The creation of new securities completes markets, and impacts information generation and liquidity. A major innovation in the fixed-income and credit markets since the turn of the century is the introduction of the credit default swap (CDS), a credit insurance contract with a payoff linked to that of the default or change in credit characteristics of an underlying reference bond or issuer. It is only to be expected that the advent of the CDS market would have resulted in a change in the information environment, likely favorable, for the underlying bonds. In this paper we examine whether the introduction of CDS improved the secondary corporate bond market in terms of its underlying efficiency, market quality and liquidity. ${ }^{1}$ Taking a time-series perspective we examine the following question: did an issuer's bonds become more efficient and liquid after CDS trading was instituted on the reference instruments of the issuer? From a cross-sectional perspective we query: are bonds of firms with traded CDS contracts more efficient and liquid than bonds of firms without any CDS contracts?

Did corporate bond trading decline after the introduction of CDS because traders were able to implement a credit view better and more cheaply in the CDS markets? Figure 1 shows the mean size of bond trades relative to the date of inception of CDS trading for our sample of firms with traded CDS contracts benchmarked to a control sample of firms with no CDS introduction; we observe that the mean trade size falls significantly following CDS introduction indicating an evident decline in secondary bond market activity. Similarly, Figure 2 depicts a sharp drop in mean turnover of bonds of issuers with CDS contracts once CDS trading begins, whereas there is no appreciable change for control sample bonds.

Figure 1: here.

Figure 2: here.

\footnotetext{
${ }^{1}$ Most equity options are exchange traded, and hence the introduction of an equity option is decided by the corresponding options exchange depending upon factors such as trading volume, market capitalization and turnover of the underlying stock. In contrast, the CDS market is OTC over the period of this study and hence decentralized; CDS introduction is initiated by dealer banks depending on factors such as size of outstanding debt of an issuer, underlying credit risk of the issuer, and demand for credit protection. More recently, CDS contracts are being moved to a centralized clearing system, and are becoming exchange traded.
} 
Figures 1 and 2 indicate that bond trading may have declined, but it is likely that bond market efficiency improved if the CDS market generated useful information that was quickly reflected in bond prices. As our empirics will show, the informational efficiency of corporate bonds is poor both before and after the advent of CDS trading, and interestingly, bonds become more inefficient after CDS trading commences. This suggests that the CDS markets had a detrimental effect on bond market efficiency. Bond market quality showed no signs of improvement after CDS introduction. Also, using various measures of liquidity we find that post-CDS, on a relative basis, more liquidity attributes deteriorated than improved.

The prior literature on bond market efficiency has examined lead-lag relationships between corporate bonds and equity markets as a way of assessing the relative efficiency of bonds to equity (e.g., Kwan (1996), Hotchkiss and Ronen (2002), Downing, Underwood and Xing (2009), Ronen and Zhou (2009)), and Ismailescu and Phillips (2011); the findings, as we discuss in the next section, are mixed. Our goal in this paper is different from that of the prior literature. Whereas we do revisit the issue of bond market efficiency, our goal is to assess what role the CDS markets played vis-a-vis the bond markets, and to determine whether CDS trading was beneficial or detrimental to the underlying bond markets on criteria such as efficiency, quality, and liquidity. We examine these criteria before and after the inception of CDS trading when benchmarked against a control sample of firms with no CDS introduction.

Our econometric specifications extend earlier work, necessitated by the increasing complexity of the fixed-income markets. Corporate bonds contain call and amortization features, various default triggers, and conversion and put options. Therefore, in this paper we consider multivariate lead-lag relationships of corporate bond returns to returns on various other securities that would also be incorporating issuer-specific and systematic market-wide information. The issuer-specific information includes (a) the equity return of the issuer (as equity value is an input to deriving a firm's credit spread in structural models pioneered by Merton (1974)) and (b) the CDS spreads of the issuer (to measure the underlying credit risk of the firm). We consider aggregate systematic variables such as (c) the implied volatility embedded in equity index options (to capture information about market-wide business and credit risk) and (d) the return on interest rate swaps (which are increasingly used as benchmark interest rate instruments). Hence, a wide range of factors are used to assess the efficiency of bonds. In addition, (e) lagged corporate bond returns may explain current returns if bonds are weak-form inefficient.

In order to judge whether or not the introduction of CDS was beneficial in enhancing bond market efficiency, we run relative efficiency tests for periods prior to the commencement of CDS trading for a firm, and compare these results to the period after CDS trading com- 
mences. By regressing bond returns on contemporaneous and lagged values of these issuerspecific and aggregate variables, and testing for the joint significance of the lagged variables, we determine whether bonds are relatively inefficient compared to other securities that are also impounding information about the firm. Using this approach, we find that corporate bonds became increasingly inefficient as CDS markets matured. Our empirical analysis of bond market efficiency is robust and varied in the range of econometric tests and data configurations. We analyze bonds individually and also jointly in panel data analyses. We control for endogeneity in the decision to introduce CDS and confirm that there is nothing specific about the firms for which CDS trading commences that drives our results, such as firms that are expected to become more illiquid or decline in credit quality. ${ }^{2}$ To complement the lagged regression analyses, we undertake difference-in-differences tests where we augment our sample of pre- and post-CDS bond transactions for CDS issuers with control samples of bond transactions by CDS non-issuers (firms with no CDS introduction). This analysis also provides evidence of declining bond market efficiency after CDS introduction. We also cut the data into various sub-samples (eliminating the financial crisis period, removing periods of nascency in the CDS market, examining subperiods of maturity in the CDS trading of a reference issuer, examining if the results differ for liquid versus illiquid bonds, vary by firm size, and by ratings and maturity) and find that the results hold for these sub-samples as well. In short, the decline in efficiency of bond markets post-CDS persists across various sub-samples and for alternate robust specifications.

Did CDS trading improve the accuracy of bond prices? Following Hotchkiss and Ronen (2002) we implement the market quality measure $(q)$ of Hasbrouck (1993). Hasbrouck's measure examines the discrepancy between efficient prices and transaction prices to assess the extent of pricing error. The inverse of the variance of pricing error is a metric of market quality. Whereas this metric is related to market efficiency, its focus is on whether prices accurately impound information. We compute $q$ for bonds before and after the advent of CDS trading. The measure does not improve after CDS trading begins, suggesting that CDS markets did not enhance bond market quality.

Did bond market liquidity respond favorably to the inception of CDS? We compute several proxies for liquidity before and after the introduction of CDS trading. Our metrics include the number and dollar volume of bond trades, turnover, the LOT illiquidity measure of Lesmond, Ogden and Trzcinka (1999), the well-known illiquidity metric of Amihud (2002) and the related Amivest liquidity measure, the spread illiquidity measure of Roll (1984), the covariance illiquidity measure of Bao, Pan and Wang (2011), and the zeros impact and Roll

\footnotetext{
${ }^{2}$ In fact, we find that firms that are of better quality and have more liquid equity are more likely to be selected for CDS introduction.
} 
impact illiquidity measures based on Goyenko, Holden and Trzcinka (2009). Many trading and price impact measures remain unaffected by inception of CDS markets; amongst metrics that changed, more liquidity attributes deteriorated after the introduction of CDS than those that improved. Overall, there is no evidence that CDS introduction improved the liquidity of the underlying bonds.

Unlike equity markets that have much higher trading frequencies, examining these properties of bond markets is complicated by the fact that bonds are thinly traded, and consecutive days of trading may not always exist in order to compute returns for our tests. In order to ensure that available data is used to the best extent possible, we develop alternative approaches to augmenting the data thereby resulting in larger data sets. The procedures are described in Section 3 and Appendix B. Re-running our analysis on an augmented data set confirms the robustness of our empirical analyses. Taken together, the results suggest that CDS introduction did not improve secondary bond market efficiency, quality or liquidity.

What explains our results? One possible explanation is that price discovery mainly occurs in the CDS market because of micro-structure factors that make it the most convenient location for the trading of credit risk; second, there are different participants in the cash and derivative markets who trade for different reasons (e g., Blanco, Brennan and Marsh (2005)). The CDS market involves very active trading and is mostly dominated by institutional players, and hence constitutes a highly likely venue for all informed trading. ${ }^{3}$ At the same time, the corporate bond market is significantly less liquid; bonds are traditionally held by buy-and-hold investors. Further, with the proliferation of the CDO securitization market, corporate bonds were increasingly parked inside pools and were not actively traded. For these reasons, as institutional investors migrated to the CDS market over time, corporate bond markets became less liquid and active (though TRACE mandates did improve bond market liquidity somewhat; e.g., Edwards, Harris and Piwowar (2007), Bessembinder, Maxwell and Venkataraman (2006)). When we track the extent of trading by institutions before and after CDS introduction, we find evidence of a likely demographic shift by large institutional traders from trading bonds to trading CDS in order to implement their credit views, resulting in declining efficiency, market quality, and liquidity in bond markets.

Our findings echo earlier results found in option markets, where the price discovery role of options is more pronounced when the liquidity of the option market is higher compared to that of the stock market, when options provide higher leverage, and when the probability of informed trading is high (Easley, O'Hara and Srivinas (1998)).

\footnotetext{
${ }^{3}$ BIS indicates that more than $95 \%$ of CDS transactions occur between financial institutions.
} 
Informed trading and price discovery in credit markets now also occurs in CDS markets, in addition to bond markets. Credit auctions will also enhance the information in bond markets as clarity about recovery values increases (Gupta and Sundaram (2012)). Recent global OTC derivative market reform, in particular the regulatory efforts in the US spearheaded by CFTC and SEC, recognize the important role of CDS markets vis-a-vis the bond markets and it remains to be seen how new regulations will impact the bond markets. ${ }^{4}$ CDS trading is moving to centralized clearing counterparties (CCCs) where the techniques in this paper may be applied in future work to assess whether the opening of a CCC has a beneficial impact on bond markets.

The paper proceeds as follows. In Section 2 we review related work and distinguish our goals and methodology from earlier research. Section 3 describes the data set we employ. This section is complemented by Appendix B that explains our new approach to creating non-overlapping returns with a view to utilizing the entire data set for analysis, particularly for robustness tests. Section 4 presents tests of bond market efficiency, and the finding that CDS markets may have been detrimental to bond market efficiency. We explore alternative cuts of the data set and variations of specifications (such as difference-in-differences tests, controls for endogeneity and fixed effects, and tests across sub-samples) as robustness tests and show that the main findings about decline in efficiency are preserved. Section 5 explores the impact of CDS trading on bonds through the lens of Hasbrouck (1993)'s q-measure, and finds no improvement in market quality. Section 6 examines how CDS trading impacted the liquidity of underlying bonds using several metrics, and there is no evidence of liquidity enhancement in bond markets. In Section 7 we document one likely mechanism by which CDS introduction may hurt the efficiency of bond markets - the demographic shift by large institutional traders from trading bonds to trading CDS. Conclusions and discussion are offered in Section 8.

\section{Background and Related Literature}

Early work on bond market efficiency focused on whether bond prices rapidly and accurately incorporated relevant information about issuer firms. A simple way to examine this proposition is to look at whether information that is incorporated into equity prices is also incorporated fully into bond prices in a timely manner. Such an analysis does not presuppose

\footnotetext{
${ }^{4} \mathrm{CDS}$ markets were blamed for naked shorting and excessive speculation, lowering capital requirements for FIs, lowering underwriting standards in ABS market, and lowering monitoring incentives for banks, among others (Source: ISDA). The Dodd-Frank Act in the US introduces regulatory measures such as dealer collateral requirements, promoting transparency, setting up centralized clearing houses, regulating naked CDS positions, and imposing position limits.
} 
that the equity markets are efficient, yet tests whether the bond market is less efficient than the equity market.

For example, Kwan (1996) finds that, although there exists a negative contemporaneous relationship between changes in bond yields and stock returns, stocks lead bonds in incorporating firm-specific information, suggesting that bonds are less efficient than stocks of issuing firms. In contrast, Hotchkiss and Ronen (2002) find individual bonds to be as informationally efficient as equity in rapidly responding to event-driven news, and market quality is no different for bonds than for the corresponding underlying stocks. ${ }^{5}$

The concurrent introduction of TRACE and trading in CDS suggests various underlying mechanisms that might impact the efficiency and liquidity of the bond market. Hotchkiss and Ronen (2002) suggest that their finding of improved bond market efficiency emanates from greater price transparency induced by TRACE. Other effects of TRACE that may have an unintended deleterious effect on bond markets may be envisaged. It is possible that TRACE generated information that spurred the CDS markets to the detriment of the bond markets. Or, TRACE enhanced bond market transparency, driving down dealer margins, making it unprofitable for market makers to trade in bond markets. This incentivized large players to move to the CDS markets instead, resulting in a drop-off in liquidity and efficiency in bond markets. The empirical analysis in this paper parse some of the equivocal effects of price transparency regulations in the bond markets. We find in favor of the latter effect, complementing the results in Goldstein, Hotchkiss and Sirri (2007).

Downing, Underwood and Xing (2009) report that stock returns lead non-convertible bond returns at the hourly level for bonds of low credit quality. They also find convertible bonds to be less efficient than stocks for all credit qualities. Thus they conclude that bonds that are of lesser quality and have complex features are more likely to be inefficient. However, Ronen and Zhou (2009) argue that the corporate bond market is not necessarily slower than the equity market in processing information and that it serves as an important venue for information-based trading, particularly when stock market liquidity is low. In these instances, bond trades are found to fully incorporate all information content in earnings surprises before significant stock market reactions occur.

Previous work has also examined the source of linkages between bond and equity markets. For example, Gebhardt, Hvidkjaer and Swaminathan (2005) document momentum spillovers

\footnotetext{
${ }^{5}$ The authors suggest that the introduction of the fixed-income pricing system (FIPS) by the National Association of Securities Dealers (NASD) in 1994 might have enhanced bond market transparency, thereby leading to improved informational efficiency. Beginning July 2002, coinciding roughly with the start of our data, transparency has been enhanced with FIPS being rolled into a larger NASD system, the Trade Reporting and Compliance Engine (TRACE).
} 
from equities to investment grade corporate bonds of the same firm. In addition, corporate news events such as mergers, takeovers, new debt issues, and/or stock repurchases involving wealth transfer to equity holders can further induce linkages between bonds and underlying stocks (Alexander, Edwards and Ferri (2000), and Maxwell and Stephens (2003)).

There is growing evidence of the linkage between bond and CDS markets too. For instance, Hull, Predescu and White (2004) study the information impact of CDS spreads on bond market ratings, and find that credit spreads provide helpful information in estimating the probability of negative credit rating changes (downgrades, reviews for downgrade and negative outlooks). Blanco, Brennan and Marsh (2005) find that the CDS market leads the bond market in determining the price of credit risk. For 27 firms they examined, the CDS market contributes on average of around $80 \%$ of price discovery. In four of the remaining six cases, CDS prices Granger-cause credit spreads, suggesting price leadership. Baba and Inada (2009) find that subordinated bond and CDS spreads for Japanese banks are largely cointegrated, and the CDS spread plays a bigger role in price discovery than the bond spread as evidenced by stronger reactions of the CDS spread to financial market variables and bankspecific accounting variables than the bond spread. Norden and Wagner (2008) find that CDS spreads explain syndicated loan rates much better than spreads of similar-rated bonds.

Forte and Pena (2009) study the long run equilibrium relationships between bond, CDS and stock market implied spreads, and find that stocks lead CDS and bonds more frequently than the reverse, and the CDS market leads the bond market. Ashcraft and Santos (2009) find that CDS introduction has not lowered the cost of debt financing or loan funding for the average borrower. They further report that risky and informationally opaque firms appear to have been more adversely affected by the CDS market. However, they look at bonds at the time of issue whereas our analysis spans the life cycle of bonds pre- and post-CDS. Norden and Weber (2009) study the intertemporal relationships between CDS, stock and bond markets. They find that stock returns lead CDS and bond spread changes, and the CDS market contributes more to price discovery than the bond market; the latter effect is stronger for US than for European firms.

Recently, Boehmer, Chava and Tookes (2010) examine the implications of derivatives and corporate debt markets on equity market quality. They find that listed options have more liquid equity and more efficient stock prices. In contrast, firms with traded CDS contracts have less liquid equity and less efficient stock prices. Overall, they find that the impact of CDS markets is generally negative. Subrahmanyam, Tang and Wang (2011) examine whether the existence of traded CDS contracts increases the credit risk of the reference entities. They find that the probabilities of credit downgrade as well as bankruptcy increase 
after the inception of CDS trading on account of the empty-creditor problem.

These recent findings raise the question as to whether the introduction of CDS markets may have impaired the informational efficiency of bond markets, and we empirically assess this question in this paper. ${ }^{6}$ Unlike earlier work, our focus lies in assessing whether the inception of CDS trading was beneficial to underlying bond markets in terms of efficiency, pricing error, and liquidity. We also use an extensive data set. Our findings are mostly consistent with much of the literature in that we find corporate bonds to be relatively inefficient. In addition, we show that corporate bonds did not become more efficient after the introduction of CDS trading; efficiency, in fact, appears to have deteriorated. We find no evidence of increases in market quality, as defined by Hasbrouck's measure. We also do not observe any evidence of improvement in bond liquidity, using several different metrics, after the emergence of CDS markets.

\section{Data}

We construct a comprehensive data set of bonds and CDS trades for the period spanning the third quarter of 2001 to the third quarter of 2009. The sample period spans the years in which the CDS markets experienced rapid growth. We undertake an extensive sample construction and data-filtering process to arrive at our final data set. We first obtain corporate bond trading data from TRACE; our initial sample consists of trades in 34,900 bonds issued by 4,869 firms, resulting in 5,768,201 daily time series observations. Next we collect daily trade data on 5-year maturity CDS from Bloomberg; our preliminary sample consists of CDS trades of 620 issuing firms, amounting to 598,221 daily CDS spread observations.

We merge the data for trades on bonds and CDS with bond issue-specific data from the Fixed Income Securities Database (FISD) and with equity data from CRSP. We filter out bonds with incomplete data, and retain bonds issued between 1994 and 2007. We keep only those bonds that are US-domestic, dollar-denominated, non-convertible issues. Our final sample includes straight bonds, and bonds with call and put features. After eliminating bonds that do not belong to publicly-traded firms, and merging and matching FISD, CRSP, TRACE and CDS data sets, we end up with 1,545 bonds issued by 350 firms in our data

\footnotetext{
${ }^{6}$ There is a long history of articles examining the impact of new derivatives markets on the market for the underlying security. Studies such as Conrad (1989) and Skinner (1989) show that equity option listing results in volatility reduction for the underlying. Long, Schinski and Officer (1994) found a marked increase in trading in the underlying, but no change in price volatility. Sorescu (2000) finds positive (negative) abnormal returns for options listed during 1973-1980 (post-1980). Most recently, in sovereign bond markets, Ismailescu and Phillips (2011) provide evidence that the introduction of credit default swaps improved efficiency in the underlying bonds.
} 
set, comprising 1,365,381 transactions. The data spans the period from 2002 to 2008 and includes, on average, 884 trading days per bond issue. Appendix A provides the details of sample construction and data-filtering process. The data summary is provided in Table 1.

Table 1: here.

Our empirical test requires the joint use of data from equity, bond, CDS and volatility markets. After filtering the data for days on which concurrent observations are available on returns in the different markets under consideration, we are left with fewer observations. Details on all these breakdowns as well as the breakdowns based on pre-CDS and post-CDS partitions are provided in Panel A of Table 1. While CDS and equity markets are highly liquid and have daily returns for most of the relevant time spans (69\% and $95 \%$ of the sample for CDS and equity respectively), bond markets are far less liquid. We find that valid daily bond returns (namely, two consecutive trading days with valid bond prices) exist for only $24 \%$ of the bond transaction data of 1.36 million bond trading days, implying that more than three-fourth of the bond transaction data is sparse (that is, bond prices exist for nonconsecutive trading days only), making it harder to construct daily bond returns. Overall, only $18 \%$ of the total time-series data sample has valid (daily) returns jointly for bonds, CDS as well as stocks. Of the total of 1.36 million bond price observations, the vast majority (i.e., 1.25 million transactions or $92 \%$ of bond trading prices) occur after the introduction of the corresponding CDS, and only about $21 \%$ of such post-CDS trading days have valid returns jointly for bonds, CDS as well as stocks. The fact that the coverage period of TRACE database almost exactly coincides with the emergence of the CDS market explains why the vast majority of bond transaction observations correspond to the post-CDS period (and not before).

In Panel B of Table 1 we present definitions of the five empirical daily return variables used in our tests. These include the return on corporate bonds (computed as changes in daily yields), return on stocks, changes in CDS spreads, changes in matching maturity swap rates (used as benchmark yields), and changes in the volatility index. All results reported in this paper are based on bond returns computed using mean daily yields. Our findings and conclusions remain unaltered if we compute bond returns using median or end-of-day (last) daily yields.

Table 2 presents the classification of time-series observations on bond trading by year and by relation to CDS trading, and also the descriptive statistics and correlations of different return variables. Table 2, Panel A reports the number of bond trades with valid returns 
each year (classified based on whether these trades correspond to the period before or after the introduction of CDS on the underlying bond). From 2002 to 2008, the number of bond transactions rises at first, peaks in 2005, and declines thereafter. Panel A also reports the number of new CDS introduced by year. The vast majority of CDS are introduced in the first three years of our sample, 2002-2004 (the table excludes the 18 CDS introduced in 2001).

Table 2: here.

Given the disparate types of securities involved in our analysis, i.e., stocks, bonds, and CDS, obtaining consecutive days on which all these securities are traded is a challenge, but are nevertheless required to compute returns for the econometric tests we conduct. Of the 1,365,381 daily transaction observations, only 249,605 have valid daily returns jointly for bonds, stocks and CDS. However, our requirement is even more stringent in the empirical analysis of efficiency: we need concurrent as well as lagged daily returns simultaneously for all securities. This results in additional attrition of the sample, biasing it towards bonds that are more actively traded, have more information available and are likely more efficient (thus, this will bias the tests against a finding of inefficiency in the bond markets).

We apply two alternative sample selection criteria to parse the data for our empirical tests. The default approach, which we call "sample selection criteria 1", invokes three successive trading days requirement: transaction observations for any day $t$ are included only if all return variables exist for day $t$ as well as lagged trading day $t-1$. We also use an alternate data sampling procedure which we denote as "sample selection criteria 2"; this approach is based on a novel parsing of the data and results in more observations than criteria 1. Criteria 2 allows us to include more data for our analysis, and constitutes both an innovation in data construction for efficiency tests as well as robustness test for our main results. Appendix B provides details of the data construction procedure under criteria 2.

Table 2, Panel B reveals that available data doubles when criteria 2 is implemented. For example, from the initial total sample of 1,365,381 observations, only 198,131 observations (15\%) meet the requirement of valid contemporaneous as well as one-day lagged values of all five return variables under sample selection criteria 1 . The size of the screened sub-sample increases to 411,148 observations (30\%) under sample selection criteria 2 .

Panel C in Table 2 presents the descriptive statistics of the daily returns on bonds, CDS, stocks, benchmark swaps, and the VIX. The number of observations for bonds is indeed lower than that for the other securities, confirming that bonds trade less frequently than stocks, CDS, swaps and volatility. Panels D and E show the correlations of various return variables; 
almost all pairwise correlations are significant at the $1 \%$ level. As expected, bond returns are positively correlated to stock and benchmark swap returns, and negatively correlated to volatility and CDS spreads, both contemporaneously and lagged; bonds, therefore, reflect news shocks to other markets accordingly. Moreover, bond returns are negatively autocorrelated to lagged bond returns, suggesting that there may be frequent return reversals in the bond markets. The correlations have the expected sign for all securities - this sets the stage for more formal empirical analysis undertaken in the next section.

We invoke three adjustments to the data samples obtained under sample selection criteria 1 and 2 prior to their adoption in formal empirical tests. ${ }^{7}$

First, we balance the pre- and post-CDS samples. Panel B of Table 2 reveals that there are substantially greater number of observations for the period after the introduction of CDS than the preceding period. The pre- and post-CDS sample sizes are unbalanced because the inherent structure of the two main data sets (Bloomberg CDS trades and TRACE bond transactions) prevent us from obtaining longer pre-CDS transaction history. Most CDS introductions take place early in the chosen 2002-2008 sample period (294 of 332 or $89 \%$ of CDS introductions occur in the first 3 years). The TRACE database commences in mid-2002; hence relatively limited pre-CDS bond trade history exists for $89 \%$ of CDS introductions. To alleviate this disparity in sample sizes, we create balanced pre- and post-CDS samples for regressions underlying tests of market efficiency by truncating the post-CDS period to just two years: we eliminate all transactions that occur more than two years after CDS introduction.

Next, we impose event windows in the analysis of bond liquidity and quality. To minimize possible confounding effects of unrelated events that may arise over long time spans (say, if entire pre- and post-CDS time periods are used), we consider a four-year window $([-2,+2]$ years) surrounding the CDS introduction event to assess the impact of the event on bond quality and liquidity. Given the sparse nature of bond trades, it appears appropriate to use two years of pre-and post-CDS trades for the tests implemented. This chosen window also reconciles with the preceding balanced sample approach we adopt in tests of bond efficiency.

Finally, we use control samples to benchmark the results obtained for the bonds of firms with CDS introduction. We consider two types of control samples: (a) "pooled unmatched control sample", and (b) "pairwise matched control sample". As Goldstein, Hotchkiss and Sirri (2007) and Davies and Kim (2009) point out, both approaches of forming control samples have their own merits and applicability, and are optimal. Nevertheless, there are

\footnotetext{
${ }^{7}$ We thank the anonymous referee for beneficial suggestions on these three methodological issues.
} 
likely limitations of each approach. An unmatched pooled control sample may include bonds that are quite different from the event sample bonds, which might affect the results. On the other hand, if a pairwise matched control sample is used, results may be sensitive to the attributes used for matching and the particular choice of bonds selected. Therefore, we follow Goldstein, Hotchkiss and Sirri (2007) and use both approaches: we form two control samples of bonds by firms with no CDS introduction as follows.

To construct the pooled unmatched control sample (henceforth, pooled control sample), we aggregate, as a pooled panel, all the bond issues by CDS non-issuers: firms that did not issue any CDS until the end of 2009 and have bonds that meet the selection criteria outlined in Appendix A. An arbitrarily selected date (derived from uniform random distribution) within the range of the first and last trading dates of the bond is used as the event date for the control sample bonds.

To obtain the pairwise matched control sample (hereafter, matched control sample), for each bond issue of a CDS introducing firm, we locate the closest matching bond of a CDS non-issuer based on bond size (outstanding amount), S\&P rating (or Moody's rating if S\&P rating is unavailable), time to maturity, and firm size (total asset value). Matching is done using the values of these attributes in the fiscal quarter of CDS introduction. On an ex-post basis, the matching control firm needs to have no CDS introduction for at least two years after the matching quarter (results are unchanged if we relax this constraint). The CDS introduction date is used as the event date for both bonds in a matched pair.

We conduct empirical analysis of bond efficiency using balanced pre- and post-CDS samples and impose a four-year $([-2,+2]$ years $)$ window for tests of bond quality and liquidity. We benchmark the results against the pooled control sample if a pooled panel of all observations is used and against the matched control sample if tests rely on individual bonds.

\section{Empirical Analysis of Bond Efficiency}

In order to ascertain whether there are delays in relevant information being incorporated into bond prices, we regress contemporaneous bond returns on contemporaneous and lagged values of the following: stock returns, benchmark swap returns, changes in equity volatility (VIX), changes in CDS spreads (for the post-CDS period), as well as lagged bond returns. If the lagged variables in these regressions are jointly significant, it implies that information has been incorporated in other traded securities (issuer-specific as well as systematic), but not yet in the issuer's bonds; thereby it is evidence that the bonds are relatively inefficient 
in comparison to other traded securities.

We start with partitioned panel regressions, that is, we run separate pre-CDS period versus post-CDS period regressions. The regression model used is as follows (Panel B of Table 1 provides the variable definitions):

$$
\begin{aligned}
& \text { bndret }_{i t}=a_{i 0}+a_{i 1} \text { stkret }_{i t}+a_{i 2} \text { tryret }_{i t}+a_{i 3} \text { vixchng }_{i t}+a_{i 4} \text { cdsret }_{i t} \\
& \quad+b_{i 0} \text { bndret }_{i, t-1}+b_{i 1} \text { stkret }_{i, t-1}+b_{i 2} \text { tryret }_{i, t-1}+b_{i 3} \text { vixchng }_{i, t-1}+b_{i 4} \text { cdsret }_{i, t-1}+\varepsilon_{i t}
\end{aligned}
$$

Of course, in the pre-CDS period, the variable relating to changes in CDS spreads, cdsret, is non-existent. In the post-CDS period, we may choose to exclude this variable in order to be consistent with the regression in the pre-CDS period, or include it to better reflect the entire information set available to the bond market. In order to be agnostic on this choice, we do both, with consistent results. Moreover, we recognize that the lagged bond return is likely to be the most informative lagged variable. So we run regressions without and with lagged bond returns, and obtain similar inferences. We run all bond efficiency regressions using balanced data: we truncate the post-CDS period to just two years. Each regression implements the Newey and West (1987) adjustment for heteroscedasticity and autocorrelation.

In all regressions, we compute the $F$-statistic for the joint significance of the lagged return variables. If the lagged variables are jointly significant, it implies that the bonds are relatively inefficient. For corroboration, we create a second measure to compare the fit of a model that has only contemporaneous data on the right-hand-side of the regression (giving the "constrained" $R^{2}$ ), and the fit of a model with both contemporaneous and lagged data (yielding the "unconstrained" $R^{2}$ ). This measure is denoted

$$
D 1=1-\left(\frac{\text { Constrained } R^{2}}{\text { Unconstrained } R^{2}}\right) \in(0,1)
$$

The higher the $D 1$ measure is, the greater the extent to which current bond returns are explained by lagged information: D1 is a measure of bond inefficiency (Hou and Moskowitz (2005)). We compute this measure separately for pre- and post-CDS periods.

\subsection{Analysis of individual bonds}

First, we consider individual bonds with at least 30 valid observations (i.e., observations with simultaneous returns for bonds, stocks and CDS, if post-CDS, on two consecutive days) in both pre- as well as post-CDS periods. We obtain 45 individual bond issues for sample selection criteria 1 and 130 for criteria 2. For each bond, we use returns based on mean 
daily yields if there were more than one observed transaction during the day (Panel B of Table 1 formally defines bond returns). ${ }^{8}$ For individual bonds, we implement the regression model described above separately for pre- and post-CDS periods, without and with lagged bond returns, and compute the corresponding D1 measures. Table 3 reports the mean and median values of $D 1$ measure in the pre- and post-CDS periods. The two panels correspond to the two sample selection criteria.

Table 3: here.

We analyze the pre-CDS and post-CDS inefficiency of individual bonds based on the reported D1 measures in Table 3. For analysis done without as well as with lagged bond returns, and for both sample selection criteria, the $D 1$ metric becomes larger in magnitude in the post-CDS period. For example, the mean D1 increases from 0.33 to 0.37 (from 0.31 to 0.34 ) without lagged bond returns under criteria 1 (criteria 2), and from 0.71 to 0.82 (from 0.67 to 0.69 ) with lagged bond returns. Similar increases occur for median $D 1$ values. Furthermore, in all four cases, more individual bonds experience an increase in value of $D 1$ measure after the introduction of CDS than those that experience a decrease in value. Also, at different significance levels, lagged variables are jointly significant for a greater number of bonds in the post-CDS period. Taken together, these findings indicate that individual bonds appear to have become relatively more inefficient after the inception of CDS trading.

We recognize the limitations of small sample sizes when we consider individual bonds; given the sparseness of bond trades, few individual bonds qualify at the stringent requirement of at least 30 observations with simultaneous returns for bonds, stocks and CDS (if post-CDS) on two consecutive days in both pre- as well as post-CDS periods. We address the data sample size issue in two ways. First, in empirical analysis in the following sections, instead of focusing on individual bonds, we use a pooled panel of all observations aggregated irrespective of the identity of the bonds. This default pooled panel obtained after applying various filters in Appendix A consists of 198,131 observations and constitutes sample selection criteria 1. Second, we extend the data using the procedure presented in Appendix B; the resultant pooled panel consists of 411,148 observations and constitutes sample selection criteria 2. Therefore, the empirical tests in the following sections use reasonably sized samples, even though certain additional filters (such as truncation of post-CDS data) do reduce the samples. ${ }^{9}$

\footnotetext{
${ }^{8}$ All results reported in this paper use bond returns based on mean daily yields. As robustness checks (not reported), we redo all regressions using bond returns computed based on median and end-of-the-day (last) daily yields instead. Qualitatively similar results obtain for all three measures of bond returns.

${ }^{9}$ Our sample size, in terms of the number of individual bonds as well as the number of time-series
} 


\subsection{Partitioned panel data analysis}

Next we conduct period-partitioned panel regressions where we implement the regression model listed above separately for pre- and post-CDS periods using the pooled panel of all observations lined up irrespective of the identity of the bonds. The post-CDS period is restricted to two years after CDS introduction. The results are reported in Table 4; Panels $\mathrm{A}$ and $\mathrm{B}$ correspond to sample selection criteria 1 and 2 respectively. We run two versions of post-CDS regressions. First, we do not include contemporaneous or lagged changes in CDS spreads in order to keep the information sets common across the pre- and post-CDS periods. Then we redo the regressions with the CDS variables included for the post-CDS period so that the new information set is used. All regressions are repeated with and without lagged bond returns.

Table 4: here.

These results in Table 4 complement the results of Table 3 by taking all bonds together in a panel. The empirical implications of the panel regressions are as follows. First, the information model is validated because bond returns are explained by equity returns and benchmark swap returns, as seen in the highly significant coefficients on these two contemporaneous variables. This implies that different securities are responding together to common information. Second, bonds are informationally inefficient relative to other securities in both pre-CDS and post-CDS periods - the lagged variables in the regressions are highly significant on a joint basis. When we include the data on contemporaneous and lagged changes in CDS spreads, both coefficients are negative and significant; this indicates that bond returns respond to information in CDS as well.

Third, across all regressions, the $F$-statistic for joint significance of the lagged variables are considerably larger in the post-CDS period in comparison to the pre-CDS period values. Although values of $F$-statistic obtained from separate regressions are not comparable, there is indication that lagged variables are probably more material in the post-CDS period. This is affirmed when we compute the $D 1$ measures for the panel regressions. As in Table 3 for individual bonds, the $D 1$ values increase in the post-CDS period relative to pre-CDS values. These suggest an increase in relative inefficiency of bonds after the inception of CDS markets.

Are these results also economically significant? To assess this, we compute the magnitude of change in bond returns when each explanatory variable is perturbed by $1 \mu$ (one mean

observations, compares favorably to those used in similar earlier work (e.g., Kwan (1996); Hotchkiss and Ronen (2002); Ashcraft and Santos (2009)). 
value) or by $1 \sigma$ (one standard deviation). We find that the impact of lagged variables on bond returns increases post-CDS for both $1 \mu$ shift and $1 \sigma$ shock analysis (for parsimony, we do not tabulate the detailed results). For example, in regressions with lagged bond returns, $1 \mu$ shifts in lagged variables increase bond returns by 20-25 basis points in the pre-CDS period and by $27-31$ basis points in the post-CDS period; in percentage terms, the $1 \mu$ shifts in lagged variables account for $70 \%$ of the innovations in current bond returns before CDS introduction and $80 \%$ after. Similar results obtain for $1 \sigma$ shocks. Hence, the economic consequences of inefficiency are material, more so in the post-CDS period.

\subsection{Joint panel data analysis}

In order to combine the period-partitioned data and use it completely, we also undertake joint panel regressions using a CDS dummy, where $C D S_{i t}=1$ if CDS was trading for a particular bond $i$ on a given day $t$, and 0 otherwise. The specification effectively keeps two series of independent variables in the panel regression, one for the pre-CDS period and one for the post-CDS period, though both are combined into one regression as follows:

$$
\begin{array}{r}
\text { bndret }_{i t}=a_{i 0}+\left(1-C D S_{i t}\right) *\left[a_{i 1} \text { stkret }_{i t}+a_{i 2} \text { tryret }_{i t}+a_{i 3} \text { vixchng }_{i t}\right] \\
+\left(1-C D S_{i, t-1}\right) *\left[b_{i 0} \text { bndret }_{i, t-1}+b_{i 1} \text { stkret }_{i, t-1}+b_{i 2} \text { tryret }_{i, t-1}+b_{i 3} \text { vixchng }_{i, t-1}\right] \\
+C D S_{i t} *\left[c_{i 1} \text { stkret }_{i t}+c_{i 2} \text { tryret }_{i t}+c_{i 3} \text { vixchng }_{i t}+c_{i 4} \text { cdsret }_{i t}\right] \\
+C D S_{i, t-1} *\left[d_{i 0} \text { bndret }_{i, t-1}+d_{i 1} \text { stkret }_{i, t-1}+d_{i 2} \text { tryret }_{i, t-1}\right. \\
+ \\
\left.+d_{i 3} \text { vixchng }_{i, t-1}+d_{i 4} \text { cdsret }_{i, t-1}\right]+\varepsilon_{i t}
\end{array}
$$

A single regression applies to a combined panel of pre- and post-CDS observations, but we obtain separate coefficients for pre- and post-CDS periods. We implement this regression without and with lagged bond returns under the two sample selection criteria. For brevity, we do not tabulate the results; we summarize the key findings as follows. First, all contemporaneous variables, except changes in volatility, are significant and bear expected signs. Second, in the pre-CDS period, not all lagged variables are significant, even though they are jointly significant. But, in the post-CDS period, all lagged variables are significant, individually and jointly. Third, the $F$-statistic for the joint significance of lagged variables is significant in pre- as well as post-CDS periods, with considerably larger values observed for the post-CDS period. For example, in regressions without lagged bond returns, the value of this $F$-statistic is 4.44 (5.03) in the pre-CDS period under criteria 1 (criteria 2), and 36.18 (33.74) in the post-CDS period; all four values are significant at $1 \%$ level. Thus, we find no evidence of improvement in bond market efficiency with the advent of CDS trading; in fact, our results, on the contrary, suggest a decline in efficiency. 
We implement a variation of the preceding regression that allows us to tease out the incremental post-CDS effects instead of merely separating the results for pre- and post-CDS periods. We run joint panel regressions with CDS dummy interactions as follows:

$$
\begin{aligned}
\text { bndret }_{i t}=a_{i 0} & +\left[a_{i 1} \text { stkret }_{i t}+a_{i 2} \text { tryret }_{i t}+a_{i 3} \text { vixchng }_{i t}\right] \\
+ & {\left[b_{i 0} \text { bndret }_{i, t-1}+b_{i 1} \text { stkret }_{i, t-1}+b_{i 2} \text { tryret }_{i, t-1}+b_{i 3} \text { vixchng }_{i, t-1}\right] } \\
+ & C D S_{i t} *\left[c_{i 1} \text { stkret }_{i t}+c_{i 2} \text { tryret }_{i t}+c_{i 3} \text { vixchng }_{i t}+c_{i 4} \text { cdsret }_{i t}\right] \\
& +C D S_{i, t-1} *\left[d_{i 0} \text { bndret }_{i, t-1}+d_{i 1} \text { stkret }_{i, t-1}+d_{i 2} \text { tryret }_{i, t-1}\right. \\
& \left.+d_{i 3} \text { vixchng }_{i, t-1}+d_{i 4} \text { cdret }_{i, t-1}\right]+\varepsilon_{i t}
\end{aligned}
$$

In this specification, all explanatory return variables (lagged and contemporaneous) are included twice: stand-alone and multiplied by the CDS dummy, $C D S_{i t}$ or $C D S_{i, t-1}$. By design, only the post-CDS variables get included in the interaction form. Thus, the interaction variables reflect the incremental explanatory role of the return variables in the post-CDS period relative to (i.e., over and above) that in the pre-CDS period. Consequently, this specification allows us to decompose the explanatory power of all included variables into two parts: a period-independent base effect, and an incremental post-CDS effect. We implement a single regression using the combined panel of pre- and post-CDS observations, and emphasize particular attention to the joint significance of the lagged dummy interaction variables because this subset of variables highlights any incremental dependence on past information (and hence reveal the decline in efficiency, if any), in the post-CDS period.

Table 5 reports the results of joint panel regressions with CDS dummy interaction; Panels $\mathrm{A}$ and $\mathrm{B}$ correspond to sample selection criteria 1 and 2 respectively. As before, the postCDS sample is restricted to two years after CDS introduction. We report the results of this regression without and with lagged bond returns. We do not assign any value to the variable relating to changes in CDS spreads, cdsret, in the pre-CDS period; this variable, by design, manifests only in interaction form in the post-CDS period.

Table 5: here.

Panels A and B of Table 5 reveal that, in stand-alone form, the coefficients corresponding to lagged bond, stock, and benchmark swap returns are significant and depict expected signs. The interaction variables corresponding to contemporaneous stock and CDS returns, and lagged bond, stock and CDS returns are always significant, indicating that these returns demonstrate relatively greater incremental explanatory power after the introduction of CDS; this is confirmed by the large and significant $F$-statistics for all interaction variables considered jointly. Crucially, the $F$-statistics corresponding to lagged interaction variables always 
show very strong significance $(F$-values of $3.78,16.95,4.64$ and 13.34 , all with $p$-values less than 0.01). These reveal that lagged return variables bear significantly greater information content for current bond returns after CDS introduction compared to the pre-CDS period. Thus, we infer that bond market efficiency deteriorated after the inception of CDS trading.

We repeat the joint panel regressions with CDS dummy interaction after including fixed effects for bond issuer firm, bond issue, and calendar year. Panels C, D and E of Table 5 present a concise version of the results (we skip the regression coefficients). Fixed effects do exist for some specifications that include issuer- or issue-specific dummy variables (as indicated by the $F$-statistics for fixed effect variables). Nevertheless, even after the inclusion of different fixed effects, the values of $F$-statistics corresponding to lagged interaction variables remain almost identical to those reported in Panels $\mathrm{A}$ and $\mathrm{B}$.

To explore the economic significance of the preceding results, we impose $1 \mu$ (one mean value) or $1 \sigma$ (one standard deviation) perturbations in each explanatory return variable; the direction of perturbation depends on the sign of the corresponding coefficient in the panel regression. Then, using the regression coefficients and the imposed perturbations, we compute the resultant change (increase) in current bond returns. Panels F and G of Table 5 report a summary of the results with emphasis on the contribution of lagged interaction variables. We find that $1 \mu$ shifts in ( $1 \sigma$ shocks to) lagged return variables result in 6-13 (277626) basis points additional bond returns after CDS introduction compared to the pre-CDS period. Alternately, the contribution of changes in lagged return variables to innovations in current bond returns increases incrementally by $14-21 \%$ in the post-CDS period. ${ }^{10}$ These results confirm the statistical as well as economic significance of the decline in bond market efficiency subsequent to the introduction of CDS.

\subsection{Controlling for Endogeneity}

Dealers most likely issue CDS for a corporate entity based on certain bond issuer characteristics. To understand how dealers select the issuers to introduce CDS and how the endogeneity inherent in this choice decision might impact the empirical analysis of bond returns, we carry out a two-stage Heckman (1979) sample selection regression analysis along the lines of Mayhew and Mihov (2004), who conduct a similar analysis to examine how exchanges select a stock for option listing.

\footnotetext{
${ }^{10}$ In terms of magnitude, $1 \sigma$ shock effects dominate the $1 \mu$ shift effects because the mean-to-standarddeviation ratio of all explanatory variables are extremely small (Panel $\mathrm{C}$ of Table 2). However, in terms of the percentage effects, $1 \mu$ shift and $1 \sigma$ shock analysis yield largely similar results.
} 
We create a panel data set on a quarterly basis: each calendar quarter, we line up all CDS issuer and non-issuer firms constituting our overall sample. For each firm-quarter observation, we collect different issuer-specific variables from CRSP and COMPUSTAT (chosen variables are along the lines of Das, Hanouna and Sarin (2009)). We drop all firm-quarter observations post CDS-introduction; that is, if CDS has been introduced for a firm prior to a given quarter, we drop that firm-quarter from the analysis (since CDS introduction is no longer a choice decision for these firms). For the remaining observations, we define a CDS introduction event binary variable that takes a value of 1 if CDS is introduced for the firm during that quarter and 0 if no CDS is introduced until the end of the quarter. We obtain 332 event firm-quarters and 10,945 non-event control firm-quarters. Panel H of Table 5 reports the results of the first stage probit of the CDS introduction event on various issuer attributes along with the comparison of mean values of these attributes for CDS issuers vs. CDS non-issuers.

Interestingly, the unconditional comparison of means as well as the results of a probit reveal that CDS is more likely to be introduced for older, larger, more profitable firms with higher equity liquidity and lower equity volatility (or, in short, for less distressed firms). From a distress perspective, only the positive coefficient of leverage and the negative coefficient of Tobin's Q are along expected lines. But even these two attributes manifest their effects only in the multivariate setup; the values of both variables for CDS issuers vs. non-issuers are not significantly different on an unconditional basis. The results remain unchanged if we use the value of equity capitalization instead of total value of all assets, and the book-to-market value of equity instead of Tobin's Q.

For the second step of the two-stage procedure, we first compute the probability of CDS introduction as the predicted probability of the dependent variable in the probit specification. If CDS has already been introduced for a firm as on a given observation date, we impute a value of 1 to the probability of CDS introduction. We repeat the joint panel regressions of Panels A and B with the probability of CDS introduction as an additional explanatory variable. The results are reported in Panel I of Table 5 (we ignore the coefficients of other explanatory variables).

Notwithstanding the inclusion of implied probability of CDS introduction as an additional explanatory variable, in all four specifications the joint significance of the lagged interaction variables, as captured by $F$-statistics, are almost the same as those reported in Panels A and B. Hence, the inference of deterioration of bond market efficiency following CDS introduction remains robust to controls for endogeneity. We also find that the implied probability of CDS introduction has a negative impact on bond returns; that is, bond returns are lower if CDS 
has already been introduced or the prospect of impending CDS introduction is high. This effect is corroborated in work by Subrahmanyam, Tang and Wang (2011) who find that probabilities of credit downgrades as well as bankruptcies increase after the inception of CDS trading.

\subsection{Difference-in-differences tests}

The analysis so far reveals that bond returns demonstrate greater dependence on the lagged information set following the introduction of CDS. However, such inferences of deteriorating bond market efficiency are likely to be unconvincing if there are permanent differences between firms with and without CDS introduction (as the preceding probit analysis indicates), or if there exist trends (such as systematic evolution in the type of firms issuing bonds, or fundamental shifts in market or economic conditions) over the time-period of study. Empirical inferences of market inefficiency can be disentangled from such contaminating effects through the use of difference-in-differences (DiD) tests that entail the comparison of CDS introducing firms with a control group of firms with no underlying CDS in a single combined panel.

To implement the DiD tests, we augment our sample of pre- and post-CDS bond transactions for CDS issuers with control samples of bond transactions by CDS non-issuers (firms with no CDS introduction). The sample of observations for CDS issuers are obtained from sample selection criteria 1 and 2. Each is merged with the matched as well as pooled control sample. For the four combined samples so obtained, we run the following regression ${ }^{11}$ :

$$
\begin{aligned}
\text { bndret }_{i t}= & \alpha_{i}+\beta_{1} C V_{i}+\beta_{2} L V_{i}+\beta_{3} C D S_{i t} * C V_{i}+\beta_{4} C D S_{i, t-1} * L V_{i} \\
& +\beta_{5} E_{i} * C V_{i}+\beta_{6} E_{i} * L V_{i}+\beta_{7} E_{i} * C D S_{i t} * C V_{i}+\beta_{8} E_{i} * C D S_{i, t-1} * L V_{i}+\varepsilon_{i t}
\end{aligned}
$$

where

$$
\begin{aligned}
& C V_{i} \equiv\left\{\text { stkret }_{i t}, \text { tryret }_{i t}, \text { vixchng }_{i t}, \text { cdsret }_{i t}\right\} \\
& L V_{i} \equiv\left\{\text { bndret }_{i, t-1}, \text { stkret }_{i, t-1}, \text { tryret }_{i, t-1}, \text { vixchng }_{i, t-1}, \text { cdsret }_{i, t-1}\right\} \\
& C D S_{i t}=1 \text { if post-CDS period and } 0 \text { if pre-CDS period } \\
& E_{i}=1 \text { for event sample of CDS-issuers and } 0 \text { for control sample of non-issuers }
\end{aligned}
$$

$C V_{i}$ denotes the set of contemporaneous return variables and $L V_{i}$ encompasses one-day lagged return variables. For the sample of CDS issuers as well as the matched control sample of CDS non-issuers, transactions are classified into pre- and post-CDS periods $\left(C D S_{i t}=0\right.$ versus

\footnotetext{
${ }^{11}$ The DiD regression is an extended version of the joint panel regression underlying Table 5: if we retain only the $E_{i}=1$ observations, the DiD regression collapses into the second regression reported in Section 4.3 .
} 
1) based on the actual CDS introduction date. For each bond in the pooled control sample of CDS non-issuers, an arbitrarily selected date (derived from uniform random distribution) within the range of the first and last trading dates of the bond is used to categorize pre- and post-treatment observations. ${ }^{12}$ As before, post-CDS sample is restricted to two years.

We implement eight different DiD regressions (2 sets of CDS observations $\times 2$ control samples $\times$ regressions without and with lagged bond returns). Table 6 reports the $F$-statistics (and associated $p$-values) corresponding to the joint significance of various subsets of explanatory variables. The $\beta$ coefficients capture differences in relative explanatory power of contemporaneous and lagged variables for event sample versus control sample bonds and between pre- and post-CDS periods. The significance of coefficients $\beta_{2}, \beta_{4}, \beta_{5}+\beta_{6}, \beta_{6}$, and $\beta_{8}$ are of particular interest to us. Coefficient $\beta_{2}$ reveals the unconditional relevance (independent of sample-type and time-period) of lagged variables for current bond returns. Coefficient $\beta_{4}$ reflects sample-independent time-trends in the significance of lagged variables, that is, whether lagged variables become more material in the post-CDS period for the joint sample of bonds of CDS issuers and non-issuers. Coefficients $\beta_{6}$ and $\beta_{5}+\beta_{6}$ intimate time-independent fundamental differences between event and control samples - whether bond returns of CDS issuers incorporate lagged and contemporaneous information differently from those of CDS non-issuers in pre- as well as post-CDS periods. The key coefficient of interest, $\beta_{8}$ informs the incremental effect of lagged variables in the post-CDS period relative to the pre-CDS period over and above similar time-trend effects within the control group. A significant $\beta_{8}$ provides conclusive evidence of post-CDS deterioration of bond efficiency.

Table 6: here.

We find that $\beta_{2}$ is significant in all eight specifications; this implies that, unconditionally (i.e., without distinguishing event and control sample bonds, or pre- and post-CDS status), lagged variables always impact current bond returns. Bond markets, in general, are inefficient. Coefficient $\beta_{4}$ is marginally significant (i.e., significant at the $5 \%$ level for 4 of the 8 cases); this indicates that, for the joint event and control sample, lagged variables probably influence current bond returns more in the post-CDS period. There is a weak overall deterioration of bond efficiency over time. Since $\beta_{5}+\beta_{6}$ are always significant, we infer that bonds of CDS issuers always react to contemporaneous and lagged information from other securities to a greater extent than control sample bonds. In particular, the significant $\beta_{6}$ divulges that,

\footnotetext{
${ }^{12}$ The choice of an arbitrary treatment date for the pooled control sample is motivated by similar approach adopted in event study literature. Results of DiD regressions remain unaltered when we implement different simulation runs to generate distinct values of these arbitrarily selected dates. As a check for robustness, we employ two alternate choices for the treatment ("non-event") date for the pooled control sample bonds: (a) the midpoint between the first and last trading dates of each bond, and (b) the fixed midpoint of our data sample, 30 June 2005. Results of DiD regressions remain materially unaffected under all three choices.
} 
irrespective of CDS introduction status, lagged variables always bear greater impact on bond returns of CDS issuers than those of non-issuers. Bonds of CDS issuers appear fundamentally different in terms of the price discovery process (i.e., in incorporating information).

Most importantly, $\beta_{8}$ is convincingly significant in all eight implementations of DiD regressions. The $F$-statistics corresponding to $\beta_{8}$ depict values of $4.17-5.00$ without lagged bond returns and 11.32-17.14 with lagged bond returns; the corresponding $p$-values are always less than 0.01. Lagged return variables influence bond returns of CDS issuing firms to a greater extent in the post-CDS period compared to the pre-CDS period even after controlling for time-trends and differences between CDS issuers and non-issuers. To elaborate, since $\beta_{2}$, $\beta_{4}, \beta_{6}$ and $\beta_{8}$ are all significant, we can assert that the event of CDS introduction significantly deteriorates the efficiency of underlying bonds, even though (a) bonds are inherently inefficient, (b) there is a likely decline in efficiency of all bonds over time, and (c) bonds of CDS issuers are fundamentally different in terms of price discovery; the observed decline in efficiency is robust even after controls for these three accompanying effects.

\subsection{Joint panel regressions over sub-samples}

As additional tests for the robustness of our findings, we now implement the joint panel regressions with CDS dummy interactions for different sub-samples formed based on time period and firm- and issue-specific attributes. Table 7 reports the values of different $F$-statistics for various sub-samples and different test specifications. We focus particular interest on the $F$-statistic corresponding to the lagged interaction variables which captures the incremental significance of lagged variables in the post-CDS period relative to the pre-CDS period.

Table 7: here.

\section{Effect of the financial crisis}

The last two years of our data sample, 2007-2008, overlap the financial crisis period. If the financial crisis resulted in unexpected credit and liquidity shocks to financial markets, we expect a drying up of liquidity in equity and bond markets. A large decline in liquidity is likely to cause delays in relevant information being incorporated in security prices. Is the observed post-CDS decline in bond efficiency mainly an outcome of the financial crisis?

To test this proposition, we drop the crisis years 2007 and 2008 from our sample, and repeat the joint panel regressions. We find that the values of $F$-statistics corresponding to lagged interaction variables are almost identical to those reported in Panels A and B of Table 5, and 
remain strongly significant. Our results are not materially influenced by the financial crisis; increased post-CDS dependence on lagged information persists even for non-crisis periods.

\section{Effect of nascency of the CDS market}

The initial years of any financial innovation are likely to be characterized by uncertainty, gradual evolution and limited informational impact. In the nascent phase, we may expect CDS contracts to be thinly traded and slow in incorporating changes in credit views about the underlying firm. The low liquidity and slow price discovery in the CDS market, in turn, is likely to have adverse effects on the price discovery process in the underlying bond market. Do the observed post-CDS increase in bond inefficiency apply only to the nascent phase of this financial innovation, and disappear after this market segment evolved?

We do not have trading data or related variables in our CDS data set to enable us track the evolution of CDS markets. Instead, we examine the posed question by applying Table 5 regressions to two separate sub-samples - the nascent three-year sub-period 2002-2004 and the post-incubation sub-period after eliminating the initial years 2002 and 2003. First, in results not tabulated, we find that the coefficients and $p$-values corresponding to CDS returns (cdsret) are similar for regressions over the two sub-samples. So the price discovery in bonds arising from CDS markets appears largely unchanged over time. Next, Table 7 reveals that the $F$-statistics corresponding to lagged interaction variables are strongly significant for both sub-samples (the magnitudes are smaller for the later sub-sample, but statistical significance is not different across the two sub-samples). Thus, our results are not driven by the infancy of the CDS market in the initial years of our sample.

\section{Effect over time after introduction of CDS}

The aforementioned nascency effects may apply, not only to aggregate financial innovations like emergence of a new market segment, but also to first time issuance of a security for individual firms. To elaborate, when a CDS contract is introduced for a specific firm, the initial years may depict low liquidity and slow price discovery, and efficiency probably improves in the subsequent years. All efficiency results reported so far are based on two-year post-CDS data (for balancing purposes, as discussed). Is the decline in bond efficiency after CDS introduction a short-term negative effect at firm level that fades away over longer periods?

To test this proposition, we form sub-samples by including only those bond transactions that occur within 1-, 2- and 3-years after the introduction of CDS. For these three subsamples and an unrestricted sample that retains all post-CDS observations, we implement joint panel regressions. In Table 7 , we find that lagged interaction variables are not significant 
when we use only one year of post-CDS data and regressions do not include lagged bond returns; however, the $F$-statistics corresponding to lagged interaction variables are strongly significant in the remaining 13 cases. Even when we use an unrestricted post-CDS horizon, the post-CDS increase in dependence on lagged information set is significant. Therefore, we can reject the hypothesis that the decline in bond efficiency after CDS introduction at firm level is a short-term effect and efficiency improves in the long run.

\section{Effect of underlying bond liquidity}

Efficiency in price discovery and liquidity are inherently correlated. A thinly traded security is likely to be slow in incorporating new information. For example, Chordia, Sarkar and Subrahmanyam (2011) document a strong link between lead-lag relations (autocorrelations) in returns and illiquidity of small-cap equities. Similarly, we may expect a positive relation between the observed findings of post-CDS declines in efficiency and underlying bond illiquidity. Does the introduction of CDS adversely affect the informational efficiency of less liquid bonds while maintaining (or improving) the efficiency of widely traded issues?

To address this question, using the median values of total bond amount outstanding (a commonly accepted bond liquidity attribute) in the year of CDS introduction, we classify all transaction observations into low and high amount outstanding (liquidity) portfolios and repeat the joint panel regressions. We find that the $F$-statistics corresponding to lagged interaction variables are large and significant for both liquidity portfolios (and not very dissimilar in values). This implies that CDS introduction had an adverse impact on the efficiency of bonds irrespective of the underlying liquidity. We explore the impact of CDS introduction on bond liquidity in detail in Section 6 .

\section{Effect of firm size}

Smaller firms are inherently more risky, are less likely to be covered by informed institutional market participants, and their bonds are more likely to be lower rated and less liquid. Thus, along the lines of Chordia, Sarkar and Subrahmanyam (2011), it may be expected that bonds of smaller firms are less efficient. Is the increased dependence on lagged information following the introduction of CDS greater for bonds of smaller firms than those of larger firms?

To this end, based on the median values of equity market capitalization in the year of CDS introduction, we classify our sample into small and large firm size portfolios, and replicate the joint panel tests for the two size-based sub-samples. We find that the Fstatistics corresponding to lagged interaction variables are large and significant for both firm size portfolios. The dependence on lagged information, and hence inefficiency, increases after 
the introduction of CDS for bonds of smaller as well as larger firms.

\section{Effect of bond ratings and maturity}

Default risk and duration are key determinants of bond returns, and also influence bond liquidity. For example, higher rated and shorter maturity bonds are more liquid. Since efficiency and liquidity are likely correlated, we may expect changes in bond efficiency following the start of CDS trading to depend on bond rating and issue maturity. Are the observed findings of deteriorating post-CDS efficiency more pronounced for lower rated and longer maturity bonds?

Focusing on the subset of bonds that are outstanding on the CDS introduction date (i.e., dropping issues that mature before or are offered after CDS introduction date), we form two $\mathrm{S} \& \mathrm{P} /$ Moody's ratings based portfolios (investment grade: BBB-/Baa3 and above; junk grade: $\mathrm{BB}+/ \mathrm{Ba} 1$ and below) and three maturity based portfolios (short-term: $<7$ years; medium-term: 7-15 years; long-term: >15 years). A vast majority of bonds in our sample are investment grade (90\%) and short-term (49\%). We implement the joint panel regressions for each of the five portfolios. In results not reported for brevity, we again find that the $F$ statistics corresponding to lagged interaction variables are always large and significant. Thus, all our findings are robust to controls for credit and duration risk.

\subsection{Speed of price discovery}

The results obtained so far may also be interpreted as information spillovers from other markets to the bond market. This could follow from microstructure reasons: informed traders may prefer the CDS market to bonds. Information first gets into CDS prices and then through common intermediaries (such as bond dealers) and arbitrageurs gets incorporated into bond prices with a delay. The preceding price efficiency analysis, based on the leadlag structure, will conclude that bond market is less efficient after the inception of CDS. However, it is quite possible that the information gets into bond prices quicker (or earlier) in the post-CDS world than in a scenario where the CDS market does not exist. Therefore, it is useful to consider the speed of price discovery in our analysis. ${ }^{13}$

Price inefficiency is inferred from $F$-statistics and the $D 1$ metric in regressions based on daily data and involving one-day lagged returns. On the other hand, empirical tests for speed of price discovery mandate high frequency data and multiple lags in explanatory variables. Since our data is organized as daily observations and bond trades are sporadic in nature, it

\footnotetext{
${ }^{13}$ We thank the anonymous referee for suggesting this alternate perspective.
} 
is difficult to implement rigorous tests for speed of price discovery. Nevertheless, we conduct the following two sets of simple analysis.

First, in order to establish whether our observed results merely indicate information spillover from the new information channel (CDS) to bond markets or, alternately, reveal deterioration in bond efficiency as inferred, we conduct two tests: (a) we compare the incremental post-CDS significance of lagged CDS returns versus other lagged returns based on the $F$ statistics corresponding to lagged interaction variables in the joint panel regressions of Table 5; and (b) we contrast the pre- and post-CDS D1 metric with and without CDS returns in the partitioned panel regressions of Table 4 (we do not report these results in a table for parsimony). We find that, even though lagged CDS return demonstrates the greatest explanatory power over current bond returns, other lagged variables are relevant; lagged bond returns and, to some extent, lagged stock, swap and VIX returns also bear significant impact on current bond returns. Furthermore, the $D 1$ metric always goes up following CDS introduction, and post-CDS D1 is greater than pre-CDS D1 even without the inclusion of lagged CDS returns. We can thus conclude that there may be information spillover from the emergent CDS market to the bond market, but simultaneously there is increased self price discovery (from lagged bond returns) and non-CDS cross price discovery (from lagged stock, swap, and VIX returns) in the bond market. These indicate increase in bond inefficiency.

Second, we examine the speed of price discovery by undertaking joint panel regressions based on two-day lags instead of just one-day lag. We use smaller sub-samples of data obtained from sample selection criteria 1 and 2 that consist of observations with simultaneous returns for bonds, stocks and CDS, if post-CDS, on three consecutive days. We replicate both the regressions listed in Section 4.3 with two-day lags, and compute the $F$-statistics for joint significance of 1-day and 2-day lagged interaction variables. The results (not tabulated) reveal no difference in pre- and post-CDS speed of price discovery: in both pre- as well as post-CDS periods, price discovery likely takes place within one day (i.e., only the 1-day lagged variables are significant) if lagged bond returns are ignored, and takes two days or more (i.e., both 1-day and 2-day lagged variables are significant) if lagged bond returns are included in regressions. Although this finding would be even better supported with the use of high frequency data with multiple lags, our daily analysis reveals no indication that CDS introduction increased the speed of price discovery. 


\section{Empirical Analysis of Bond Market Quality}

The preceding section reveals the detrimental impact of CDS introduction on the efficiency of the bond market. Did the inception of CDS benefit the bond markets via other channels? For example, did CDS trading improve the accuracy of bond prices? In this section we assess the accuracy of bond prices (which is henceforth referred to as bond market quality) before and after the introduction of CDS trading using the measure proposed in Hasbrouck (1993). Hasbrouck defines pricing error $s_{t}$ of a security as the difference in its log transaction price $\left(p_{t}\right)$ and its efficient log price $\left(m_{t}\right)$. The return of a security is equal to $r_{t}=m_{t}-m_{t-1}+s_{t}-s_{t-1}$. The variance of pricing error divided by the variance of return (i.e., $\sigma_{s}^{2} / \sigma_{r}^{2}$ ) is a metric of normalized pricing error. Market quality $q$ is defined as one minus this ratio, i.e.,

$$
q=1-\frac{\sigma_{s}^{2}}{\sigma_{r}^{2}}
$$

Higher $q$ denotes better market quality, i.e., lower risk of deviation of prices from their efficient levels. The formula is implemented by estimating an MA(1) process (without intercept) for security returns, i.e.,

$$
r_{t}=e_{t}-a \cdot e_{t-1}
$$

where the values $\left\{a, \sigma_{e}^{2}\right\}$ are obtained from the $\mathrm{MA}(1)$ estimation and then used in the equation for $q$ above. The resulting expression for $q$ is

$$
q=\frac{\sigma_{e}^{2}-2 a \cdot \operatorname{Cov}\left(e_{t}, e_{t-1}\right)}{\sigma_{e}^{2}+a \sigma_{e}^{2}-2 a \cdot \operatorname{Cov}\left(e_{t}, e_{t-1}\right)} \in(0,1)
$$

Details of this derivation are provided in Appendix $\mathrm{C}$ that provides more information about Hasbrouck's model.

The $q$ measure is applied to an aggregated pooled panel of all observations as well as individual bonds with at least 30 trading days with return observations in both pre- and post-CDS periods. This measure accesses more data than the efficiency regressions because it does not require concurrent data across markets (i.e., stock returns, CDS spreads, Treasury returns, or volatility data); it also does not mandate the existence of lagged bond returns for each selected observation. For example, when individual bonds are considered, the total number of bonds meeting our screening criteria is 82 , more than the 45 bonds that are available using sample selection criteria 1. 
The values of $q$ are presented in Table 8. Panel A of Table 8 employs the full pooled sample of all observations lined up as a panel irrespective of identity of the bond, and the pooled control sample is used as the benchmark sample. Panel B is based on 82 pairs of individual bonds with at least 30 pre- as well as post-CDS observations; each pair includes a bond of a CDS issuer and the closest matching bond from the matched control sample. We sub-divide each panel into two cases: one is based on an unrestricted event window (that uses all available observations) and the other is based on a restricted 4-year event window (that uses only two years each of pre- and post-CDS observations). For each scenario, we report the mean pre- and post-CDS values of the $q$ measure for bonds of CDS issuers and control sample bonds. Panel B also reports the difference-in-differences $t$-statistics. ${ }^{14}$ These statistics indicate whether the post-CDS changes in the values of $q$ within the event sample are significantly different from the post-treatment changes in value within the control sample.

Table 8: here.

For the pooled panel data of all observations, CDS introduction has little or weak detrimental impact on the market quality of the underlying bonds: quality of bonds of CDS issuers slightly decreases (from 0.92 to 0.91 and from 0.91 to 0.87 for the two different event windows) and that of control sample bonds slightly increases (from 0.90 to 0.92 or from 0.90 to 0.91 ); but these differences are not significant. When the sample of 82 pairs of individual bonds are considered, the quality of bonds of CDS issuers declines (from 0.86 to 0.82 or from 0.90 to 0.88); this decline in quality of bonds of CDS issuers is not significant in isolation, but the quality of bonds of CDS non-issuers increases substantially (from 0.84 to 0.92 or from 0.85 to 0.92). Consequently, as the difference-in-differences $t$-statistics revealed, on a comparative basis CDS introduction appears to have a detrimental impact on the market quality of the underlying bonds.

When we track the changes in the value of $q$ for each pair of individual bonds, we find that a greater fraction of bonds of CDS issuers experience a post-CDS decline in the value of $q$, whereas a larger fraction of matched control sample bonds demonstrate an increase in the value of $q$. For example, if a restricted 4-year event window is considered, subsequent to the CDS introduction, the value of $q$ decreases (increases) for 48 (33) bonds of CDS issuers, and decreases (increases) for 35 (47) control sample bonds. Similar trends are observed when an unrestricted event window is considered.

In summary, we find no evidence to show that bond market quality (or the accuracy of bond

\footnotetext{
${ }^{14}$ Since Panel A involves pooled unmatched data, difference-in-differences statistics cannot be meaningfully computed for Panel A.
} 
prices) has improved after the inception of CDS market. ${ }^{15}$

\section{Empirical Analysis of Bond Liquidity}

A likely consequence of CDS trading is that fixed-income traders no longer need to use bond markets to speculate on or hedge credit risk. The evidence in Figures 1 and 2 clearly shows the drastic changes in bond trading patterns after the introduction of CDS trading. There is a clear long-term drop-off in both trading volume and turnover. The question is: did liquidity in the bond market also suffer?

To assess this, we compute multiple measures that are either proxies for liquidity or may be highly correlated to liquidity. First, we undertake the analysis of these measures as a panel: all observations, irrespective of identity of the bond, are lined up as a panel with respect to the CDS introduction date. These results are shown in Table 9, Panel A. The pooled control sample is used as the benchmark sample in Panel A. The analysis of liquidity for individual bonds is shown in Table 9, Panel B. This sample consists of 82 individual bonds with at least 30 observations of returns in pre- as well as post-CDS periods (details in preceding Section 5). Each bond is paired with the closest matching bond from the matched control sample, and the reported difference-in-differences $t$-statistics indicate whether the post-CDS changes in the values of liquidity for bonds of CDS issuers are significantly different from the post-treatment changes in value for the matched control sample bonds.

Table 9: here.

We compute the following measures of bond liquidity and price impact ${ }^{16}$ :

1. A simple count of the number of trades. We report the total number of trades over the entire pre- or post-CDS period, and the average number of trades per day (excluding and including zero trade days).

2. The dollar volume of trading, in $\$$ million. We compute the total volume over the entire period, and the mean trade size per day and per transaction. Figure 1 plots

\footnotetext{
${ }^{15}$ For comparison to the bond markets, we also compute the market quality measure (both before and after CDS introduction) for equities corresponding to the bonds in our data set. We find that, on average, the $q$ measure is 0.98 in the pre-CDS period and 0.99 in the post-CDS period (the difference is not statistically significant). Similarly, when we examine the post-introduction quality of the CDS market itself, we obtain an average of 0.92 for the $q$ measure. Therefore, the quality of equities is much higher than that of bonds as well as CDS; the quality of the CDS market compares favorably to that of underlying bond market.

${ }^{16}$ We thank the anonymous referee for suggesting some of these measures.
} 
the trend of the mean size of each trade for the pooled sample of CDS issuers and the pooled control sample of CDS non-issuers.

3. Turnover, defined as the trading volume as a percentage of the outstanding amount of the bond issue. Again, we report the total (full period), mean daily and mean per trade values. Figure 2 plots the trend of mean turnover per transaction for the pooled samples of CDS issuers and non-issuers. ${ }^{17}$

4. The LOT measure of Lesmond, Ogden and Trzcinka (1999). We use the Das and Hanouna (2010) adaptation of the LOT measure and compute three versions of this measure separately for pre- and post-CDS periods: (i) fraction of zero return trading days, (ii) fraction of zero volume (i.e., no trade) trading days, and (iii) fraction of zero return plus zero volume trading days. The total number of trading days in the entire pre- or post-CDS period constitute the denominator of these fractions. Since non-trading days are included, the selection criteria for individual bonds is relaxed and the LOT measures reported in Panel B of Table 9 involve 257 pairs of individual bonds.

5. The zeros impact illiquidity measure. This is an extended Amihud proxy measure recommended by Goyenko, Holden and Trzcinka (2009) for low frequency data; it is based on LOT measure and is computed as:

$$
\text { Zeros } \text { Impact }_{i}=\frac{10^{6} \times(\text { number of zero return plus zero volume trading days })}{\sum_{t=1}^{D A Y S_{i}} \$ V O L_{i t}}
$$

where $\$ V O L_{i t}$ is the total daily trading volume in dollars and $D A Y S_{i}$ is the total number of trading days in the entire pre- or post-CDS period.

6. The Amihud (2002) illiquidity measure, computed as follows:

$$
\text { Amihud Illiquidity }_{i}=\frac{1}{D A Y S_{i}} \sum_{t=1}^{D A Y S_{i}} \frac{\mid \text { bndret }_{i t} \mid}{\$ V O L_{i t}} \times 10^{6}
$$

where bndret $_{i t}$ is the $i$ th bond's return on day $t, \$ V O L_{i t}$ is the total daily trading volume in dollars and $D A Y S_{i}$ is the total number of trading days in the entire pre- or post-CDS period.

\footnotetext{
${ }^{17}$ The figures reveal that, for longer windows around the event date (e.g., if the entire time horizon is considered), the changes in trade size and turnover between pre- and post-CDS periods are markedly different between the CDS sample and the control sample: we notice prominent long-term drops in mean trade size as well as per trade turnover following the introduction of CDS for the CDS issuers as compared to the control sample non-issuers. However, when we look at a narrower window of $[-500,+500]$ trading days around the event date, the changes are not appreciable. This accounts for the observed results in Table 9 where all measures are computed over a four-year $([-2,+2]$ years $)$ event window.
} 
7. The Amivest liquidity measure. This reciprocal of the Amihud measure is a recommended low frequency measure by Goyenko, Holden and Trzcinka (2009) and is computed as:

$$
\text { Amivest Liquidity }_{i}=\frac{1}{D A Y S_{i}} \sum_{t=1}^{D A Y S_{i}} \frac{\$ V O L_{i t}}{\mid \text { bndret }_{i t} \mid} \times 10^{6}
$$

where bndret $_{i t}$ is the $i$ th bond's return on day $t, \$ V O L_{i t}$ is the total daily trading volume in dollars and $D A Y S_{i}$ is the total number of trading days in the entire pre- or post-CDS period.

8. The Roll (1984) spread illiquidity estimator, computed as follows:

$$
\text { Roll Estimator }_{i}=\left\{\begin{array}{cl}
\sqrt{-\left(\operatorname{Cov}\left(\Delta P_{i t}, \Delta P_{i, t-1}\right)\right)} & \text { if } \operatorname{Cov}\left(\Delta P_{i t}, \Delta P_{i, t-1}\right)<0 \\
0 & \text { otherwise }
\end{array}\right.
$$

where $P_{i t}$ is the daily mean bond price on day $t$.

9. The Roll impact illiquidity measure. This is also an extended Amihud proxy measure recommended by Goyenko, Holden and Trzcinka (2009) for low frequency data; it is based on Roll estimator and is computed as:

$$
\text { Roll Impact }_{i}=\frac{10^{6} \times \text { Roll Estimator }_{i}}{\left(\sum_{t=1}^{D A Y S_{i}} \$ V O L_{i t}\right) / D A Y S_{i}}
$$

where $\$ V O L_{i t}$ is the total daily trading volume in dollars and $D A Y S_{i}$ is the total number of trading days in the entire pre- or post-CDS period.

10. The Bao, Pan and Wang (2011) covariance illiquidity gamma, computes as follows:

$$
\gamma_{i}=-\operatorname{Cov}\left(\Delta P_{i t}, \Delta P_{i, t-1}\right)
$$

where $P_{i t}$ is the daily mean bond price on day $t$.

All these measures are computed over a four-year $([-2,+2]$ years $)$ event window: the reported pre- and post-CDS values are based on two years of observations each. The covariances for the Roll estimator and the covariance gamma are computed on a trading day basis, and not on a calendar time basis (i.e., day $t-1$ is the previous trading day prior to the day $t$ observation, ignoring interim zero trade days, holidays and weekends). The last six measures are quite skewed (as inferred from the mean-to-median ratios); so we report the mean as well as median values for these measures. The tests for difference between means are based on $t$-tests and between medians on Wilcoxon (Mann-Whitney) rank-sum tests. 
Table 9 reveals that results are mixed as to whether the inception of CDS markets affected bond liquidity.

Quite a number of measures indicate that the liquidity of bonds of CDS issuers deteriorated subsequent to the introduction of CDS relative to the control sample bonds. These include daily and per trade turnover, median zero impact, median Amivest liquidity, mean Roll estimator, and mean and median covariance gamma (for the pooled sample of all observations in Panel A); daily and per trade turnover, and mean and median Amivest liquidity (for the 82 individual bonds in Panel B).

In contrast, the following measures support the likelihood that liquidity of bonds of CDS issuers probably improved in the post-CDS period when compared to the control sample bonds: number of daily trades, daily and per trade trading volume, and LOT zeros (for the pooled sample of all observations in Panel A); number of daily trades, and daily trading volume (for the 82 individual bonds in Panel B).

For the remaining liquidity (trading and price impact) attributes, there is no conclusive inference: either the pre-CDS and post-CDS values are not significantly different for the bonds of CDS issuers, or post-treatment trends observed for the bonds of CDS issuers are not appreciably different from similar trends for control sample bonds of non-issuers.

Overall, there is no definite evidence that CDS introduction improved the liquidity of the bonds underlying the CDS entity. If at all, on a relative basis, more liquidity attributes deteriorated than improved after the inception of CDS markets.

\section{How CDS Introduction Impacts Bonds}

What explains our results? One possible explanation for the decline in efficiency and quality of bond markets subsequent to CDS introduction is the likely migration of large institutional traders from trading bonds to trading CDS in order to implement their credit views. As seen in Figure 1 of the paper, the mean trade size drops dramatically after CDS introduction, signifying that the large institutional traders may have moved from trading bonds to trading CDS. Figure 2 supports this likely demographic shift by depicting the reduction in bond turnover after CDS introduction.

To explore this issue, we determine the extent of trading by institutions before and after CDS introduction. We track likely shifts in institutional trading in two ways. First, we examine the institutional trades in the TRACE database. In TRACE, institutional trades 
are identified by the size of the disseminated quantity of a bond issue in a completed trade transaction: trades with reported par values of $\$ 5$ million and above for investment grade (Baa3/BBB - and above) bonds or reported par values of $\$ 1$ million and above for below investment grade (Ba1/BB+ and below) or unrated bonds are classified as institutional trades. Institutional trades are relatively rare. The (unfiltered) TRACE sample of completed trades for 2002-2009 consists of 5,768,201 time-series (bond issues $\times$ trading days) observations; of these 704,612 (12.22\%) are institutional trade observations. Alternately, in our final filtered sample of 1,365,381 time-series observations, whereas 507,605 days (37.18\%) report at least one valid bond trade, only 46,234 days $(3.39 \%)$ have one or more institutional trades.

Next, we inspect the trades in the NAIC database which lists bond transactions by all insurance companies (life insurance companies, property and casualty insurance companies, and health maintenance organizations). ${ }^{18}$ Using NAIC data that spans the period 1994-2007, we obtain 76,703 trades (39,132 pre-CDS and 37,571 post-CDS) by insurances companies in the four-year $([-2,+2]$ years $)$ window surrounding the introduction of CDS for 1,379 bonds of CDS-issuing firms. We also collect the corresponding trades by insurances companies for control sample bonds of CDS non-issuers.

Table 10 reports (a) the number, volume and turnover of TRACE institutional bond trades as a percentage of all bond trades, (b) the LOT measures corresponding to TRACE institutional bond trades, and (c) the number, volume and turnover of bond trades by insurance companies in the NAIC database. Panel A presents the statistics for all observations, irrespective of identity of the bond, grouped as panel data, while Panel B focuses on 82 individual bonds (257 for the relaxed LOT measures) with at least 30 observations of returns in pre- as well as post-CDS periods. The pooled control sample is used as the benchmark sample in Panel $\mathrm{A}$, and the matched control sample in Panel B.

Table 10: here.

An examination of Panels A and B of Table 10 reveals that institutional bond trades relatively declined post-CDS. Panel A, for example, shows that proportional institutional trading volume and turnover stay unchanged for the CDS sample, whereas they go up in the control sample. Panel B affirms the more pronounced drop in institutional trades for the CDS sample compared to the control sample as suggested by the difference-in-differences statistics. The LOT measures for institutional trades relatively increase post-CDS for the CDS issuers more than that for the control sample, suggesting that liquidity in this segment of

\footnotetext{
${ }^{18}$ Campbell and Taksler (2003) report that insurance companies account for about one-third of all institutional bond holdings.
} 
the bond markets dwindled. Further, both Panels A and B highlight that the transactions by insurance companies in the CDS sample witnessed a steeper decline in trading volume and turnover compared to the control sample.

In conclusion, it appears likely that a demographic shift in bond trading is a driver of the empirical results we obtain.

In addition, we also implement the liquidity tests adopted by Bessembinder, Maxwell and Venkataraman (2006) who estimate an effective spread measure for signed insurance company trades, and decompose price changes into informational and non-informational components. For the sample of bonds by CDS issuers and the pooled control sample of bonds of CDS non-issuers, using the preceding data set of trades by insurance companies from the NAIC database, we carry out a similar two-stage analysis (results not reported here for brevity). For the informational component of bid-ask spreads, we find that there is no change in the role of private information on the price evolution of bonds for CDS issuers, but the effect of private information decreases for the control sample bonds. For the non-informational portion of bid-ask spreads, the post-CDS trade execution costs increase for bonds of CDS issuers as well as control sample bonds. The observed increase in trade execution costs reconciles with the decrease in trading activity by insurance companies documented in Table 10. Hence, we confirm that introduction of CDS resulted in an increase in bond illiquidity for institutional transactions as indicated by the effective spread measure of Bessembinder, Maxwell and Venkataraman (2006).

\section{Conclusions and Discussion}

The credit default swap (CDS) market was one of the salient new markets of the past decade. Trading in CDS has been blamed for the speculative frenzy leading to the beginning of the financial crisis in 2008 though Stulz (2010) concludes that credit default swaps were not responsible for causing or worsening the crisis. Nobelist Joseph Stiglitz went so far as to suggest that CDS trading by large banks should be banned. ${ }^{19}$ Still, the creation of new markets may have beneficial information and liquidity effects on underlying markets Conrad (1989), Skinner (1989) showed that options trading reduced volatility in underlying equity markets. In sovereign bond markets, Ismailescu and Phillips (2011) provide evidence that the introduction of credit default swaps improved efficiency in the underlying sovereign bonds.

\footnotetext{
${ }^{19}$ Reported by Bloomberg, October 12, 2009.
} 
We examine whether CDS trading was beneficial to bonds in reference names by looking at whether informational efficiency, market quality and liquidity improved once CDS trading commenced. Our econometric specification accounts for information across CDS, bond, equity, and volatility markets. We also develop a novel methodology to utilize all observations in our data set even when continuous daily trading is not evidenced, because bonds trade much less frequently than equities. The empirical evidence suggests that the advent of CDS was largely detrimental to secondary bond markets - bond markets became less efficient, evidenced greater pricing errors, and lower liquidity. These findings are robust to various slices of the data set and specifications of our tests. Our findings have bearings on the recent CDS market regulatory reform proposals and the debate surrounding the impact and usefulness of CDS markets.

Whereas we examined bond market efficiency, quality, and liquidity, this research did not examine the effect on credit, i.e., the impact on the quality of firms that experienced CDS introduction. Our endogeneity corrections did note that bond returns are negatively related to the implicit probability of CDS introduction, complementing the comprehensive analysis of this issue in Subrahmanyam, Tang and Wang (2011). Other open questions remain that are not considered in this paper. Does CDS trading make forecasting default easier for reference names than for firms on which no CDS trades? How do capital structures change for firms that have CDS traded versus firms with no CDS? How does ratings volatility change when CDS are introduced? Are firms that have CDS traded more likely or less likely to have securitized debt? And eventually, how does the trading of CDS on centralized exchanges change the information environment for CDS and bonds? These issues and questions are left for future research. 


\section{Appendix}

\section{A Bond sample construction}

The project data comes from four sources: corporate bonds (TRACE and FISD), stocks (CRSP in WRDS), CDS (Bloomberg), and swap rates and VIX (Datastream).

$\underline{\text { Step 1: TRACE data }}$

We start with the Trade Reporting and Compliance Engine (TRACE) bond transaction database which lists all over-the-counter secondary market bond transactions since July 2002 by all brokers or dealers who are member firms of Financial Industry Regulatory Authority (FINRA). We collect transaction information such as trade date, trade price, trade size, and underlying yield corresponding to all bond transactions between July 1st, 2002 and September 30th, 2009. Since TRACE reports multiple intra-day bond transactions, for each bond we aggregate all intra-day transactions into a single summary transaction observation each day. For each bond transaction date, the aggregated observation consists of number of trades; mean and total trading size; and mean, median and closing (last) daily yields and prices.

We impose certain screening criteria on the bond transaction sample. We exclude: (a) transactions identified as trade cancelations or corrections, (b) when-issued trades, (c) trades with commissions, (d) as-of-trades, (e) special price trades, and (f) trades with sale conditions. The screened sample consists of 5,768,201 transaction date observations for 34,900 bond issues by 4,869 firms.

Step 2: FISD data

Separately, from Mergent's Fixed Investment Securities Database (FISD) issuance database which includes in depth issue- and issuer-related information on all U.S. debt securities maturing in 1990 or later, we collect issuance related information such as issuance date, maturity date, offer amount, etc. for all bonds issued between 1994 and 2007. From dynamic FISD tables, we extract bond ratings and amount outstanding on the transaction date of each bond trade. For bond ratings, we use the Standard \& Poor's rating if it exists; otherwise we use Moody's rating.

Based on FISD variables, we further exclude the following bond issues: bonds with redeemable, exchangeable, convertible, sinking fund, enhancement, or asset-backed features; perpetual and variable rate bonds; medium-term notes; Yankee, Canadian, and foreign cur- 
rency issues; Rule 144a issues; TIPS, Treasuries, Munis, Treasury coupon- and principalstrips; and agency-type bonds. We retain bonds with call and put features. The FISD sample yields 11,950 U.S. domestic corporate bond issues.

Step 3: Intersection of FISD and CRSP data

Using the 6-digit CUSIP identifiers, the screened sub-sample of FISD bond issues is then merged with the Center for Research in Security Prices (CRSP) database. We eliminate bond issues that do not belong to firms with public equity, that is, do not have any matching stocks in the CRSP database. The merged FISD-CRSP sample consists of 8,291 U.S. domestic corporate bond issues.

Step 4: Intersection of TRACE and FISD-CRSP data

Based on the 6-digit CUSIP identifiers, we merge the TRACE bond transaction sample with the FISD-CRSP bond issue- and issuer-attributes sample. The merged sample consists of 843,442 trading date observations for 2,806 bond issues by 967 issuers.

Step 5: Bloomberg data

We obtain trades data on 5-year CDS from Bloomberg. Bloomberg consists of two sources of CDS data: CBGN and CMAN. CBGN is Bloomberg's own composite data, and reports the generic price data for each CDS as an average of the contributed spreads from multiple data vendors. CMAN is an external data provider that offers its pricing data on the Bloomberg terminal. We assume that the starting date of CDS spreads in Bloomberg is also the date of introduction of the CDS; the assumption is reasonable given that Bloomberg has an extensive coverage of CDS data and is recognized as a benchmark pricing source. ${ }^{20}$

We use the Bloomberg default CBGN source as the primary data; for 314 CDS issues, CBGN data is complete and is used as is. For 293 CDS, CBGN data is incomplete (largely before 2008) and is augmented with data from CMAN. For another 13 CDS, CBGN has no data and CMAN becomes the primary source of CDS spreads. Altogether, we obtain daily CDS spreads on 620 CDS issues by 620 U.S. firms for a total of 598,221 daily observations between August 3rd, 2001 and September 30th, 2009.

Step 6: Intersection of TRACE, FISD, CRSP and Bloomberg data

We merge the data obtained from TRACE, FISD, CRSP and Bloomberg to yield a composite

\footnotetext{
${ }^{20}$ Because the CDS market is new, there is no single agreed-upon source of CDS data. There are multiple vendors of data, and it is likely that the start dates differ across these data providers. To verify the robustness of our assumption, we collect the CDS inception dates from an alternate database, Markit. We run our empirical tests using these alternate starting dates; our results and implied conclusions remain unchanged.
} 
sample of 2,806 bond issues by 967 issuers and 1,987,410 time-series observations. ${ }^{21}$ Of the composite sample, 355 issuing firms (37\%) or, equivalently, 1,559 bond issues $(56 \%)$ have corresponding CDS issues.

We impose a few additional filters: (a) we eliminate 2009 data because it is incomplete; (b) we exclude 612 bond issuing firms which do not introduce any CDS till the end of 2008; (c) we remove 8,208 bond trades reported in TRACE for 28 bonds that occur after the maturity date reported in FISD; and (d) we discard 645 bond issues which have valid stock returns before July 2002 but the stock is delisted prior to the bond transaction data being available on TRACE.

Our final screened sample consists of 1,365,381 time-series observations on 1,545 bond issues by 350 issuing firms (which also had CDS introduced between 2001 and 2008).

Step 7: Augmentation with Datastream data

From Datastream, we collect daily values for the VIX index and daily swap rates for 15 different maturities (ranging between 1 and 30 years) from August 2001 through December 2008. Each bond trading date is matched to a corresponding swap rate based on linear interpolation of the two closest neighboring maturity swap yields; this yields a time-series of swap rates matching in maturity to the corresponding bond issue. The swap rates and VIX index values are augmented to our screened data sample.

The following table succinctly describes the key steps of sample construction and screening, and lists the sample size after each step.

\begin{tabular}{llccc}
\hline & & \multicolumn{3}{c}{ Number of } \\
\cline { 3 - 5 } Step & Description & Issuers & Issues & Observations \\
\hline 1.A & raw TRACE data (Jul 2002 - Sep 2009) & 4,869 & 34,900 & $40,044,493$ \\
1.B & eliminate special or cancelled trades & 4,869 & 34,900 & $34,140,337$ \\
1.C & combine all intra-day trades into a single daily & & & \\
& transaction observation & 4,869 & 34,900 & $5,768,201$ \\
\hline 4 & intersect TRACE and screened FISD+CRSP & 967 & 2,806 & 843,442 \\
\hline $6 . \mathrm{A}$ & merge TRACE+FISD+CRSP+Bloomberg & & & \\
& datasets & 967 & 2,806 & $1,987,410$ \\
$6 . \mathrm{B}$ & separate out CDS non-issuers, apply other filters & 350 & 1,545 & $1,365,381$ \\
\hline & Sample selection criteria 1* & 316 & 1,277 & 198,131 \\
& Sample selection criteria 2* & 340 & 1,469 & 411,148 \\
\hline
\end{tabular}

* Sample selection criteria 1 and 2 are discussed in Appendix B below.

\footnotetext{
${ }^{21} 1,987,410=(\#$ of bonds $) *$ (days with valid return on at least one of the three securities: bonds, CDS or stocks); hence, this number is larger than the separate daily observations reported in Steps 1, 4 and 5 .
} 


\section{B Alternate approaches to data construction}

In this Appendix we describe an alternative to the primary data sampling approach used in the paper. The primary filter of the data is explained in Section 3 and Appendix A, and is denoted "sample selection criteria 1". The extended "sample selection criteria 2" is based on the alternate approach described below.

The main objective of extending the data construction methodology of default sample selection criteria 1 is to obtain more observations for analysis, and to offer a robustness test of the key results of the paper. Under criteria 1, we retain those days on which we have three consecutive observations of all traded securities in our sample. Hence, under the alternate approach, we focus on periods of active trading, which are more likely when information is being released - these are exactly the periods when we want to test for market efficiency.

Under this extended data construction approach, we not only include those days on which we have three consecutive observations but also expand the calculation of returns to windows of time that are greater than one day between observations of transactions (i.e., observations are non-consecutive). In periods when information about the bond issuer is high, the inter-arrival time between transactions will be small, and in periods of low information, inter-arrival times will be large. So the extended data approach allows for efficiency tests on non-standard intertransaction times. The extended sample selection criteria 2 is implemented as follows.

CDS and bond trades are sporadic. The gaps in the data occur because of the absence of consecutive days when both CDS and bonds trade, precluding return calculations. Therefore, in this approach we use all dates on which both the bond as well as CDS of the firm were traded (and had observations); these dates need not be consecutive. As an illustration, suppose we have trades of the bond as well as CDS only on days $\{1,2,5,7,8,9,12,15,16\}$. For both, we compute a return series (i.e., yield changes) as $R(t, t+k)=[y(t+k)-y(t)] / k$, where $k$ is the number of days between observations and $y(t)$ is either the yield on the bond or the CDS spread. The sign of the numerator depends on whether we are looking at CDS or bonds; for bonds, a "-_" precedes the numerator. By dividing by $k$ we still obtain an average daily return, thereby constructing a non-overlapping time series of "average daily returns". Consequently, all the tests applied to daily returns remain the same, and may be applied just as in the main set of tests. It is important for the tests of bond efficiency that the information sets for contemporaneous returns and lagged returns do not overlap, and this is still maintained when we construct our return series using this approach. This approach has the advantage of focusing more on days when there was trading, i.e., days when information was more likely to be released. It also substantially increases the sample size. 


\section{Market quality measure $(q)$}

This Appendix presents a brief summary of the Hasbrouck (1993) model of market quality for a security. We retain the same notation, though our final measure is different (albeit in the same spirit).

Hasbrouck defines market quality as the inverse of the variance of the pricing error after accounting for the efficient component of returns.

The log transaction price of a security is given as

$$
p_{t}=m_{t}+s_{t}
$$

where $m_{t}$ is the efficient component (i.e., a random walk) and $s_{t}$ is the pricing error. The smaller that the variance $\operatorname{Var}\left(s_{t}\right)$ is, the higher is market quality $q$. The security's continuous return may be written as the difference of log transaction prices:

$$
r_{t}=m_{t}-m_{t-1}+s_{t}-s_{t-1}
$$

It remains to specify the processes for $m_{t}$ and $s_{t}$. The process for the former is a simple random walk, i.e.,

$$
m_{t}=m_{t-1}+w_{t}
$$

and the process for the pricing error may be information-related, i.e., related to innovation $w_{t}$, or it may be non-information related, i.e., independent of $w_{t}$ with separate innovation term $\eta_{t}$. To cover both cases, Hasbrouck posits that

$$
s_{t}=\alpha w_{t}+\eta_{t}
$$

where the information related pricing error is the case where $\alpha \neq 0$ and $\eta=0$. In the case of a non-information related pricing error, we have $\alpha=0$ and $\eta \neq 0$ instead.

We consider the first case, i.e., information related pricing errors. Substituting equations (3) and (4) in equation (2) and setting $w_{t}=(1-a) e_{t}$ and $\alpha=\frac{1}{1-a}$, we get after simplification

$$
r_{t}=e_{t}-a e_{t-1}
$$

which is an $\mathrm{MA}(1)$ process. Estimating this process on return data gives the parameters $\left\{a, \sigma_{e}^{2}\right\}$. We can see that $\sigma_{s}=a \sigma_{e}$.

Now we consider the second case, i.e., non-information related pricing errors. Setting $w_{t}=$ $(1-a) e_{t}$ and $s_{t}=\eta_{t}=a e_{t}$, and substituting these values into equation (2) results in the same MA(1) process as before, i.e., $r_{t}=e_{t}-a e_{t-1}$. Again, we note that $\sigma_{s}=a \sigma_{e}$. 
We do not need to ascertain whether the first or the second case applies, because the pricing error equation is the same in both cases. Of course, the value of parameter $a$ will vary empirically depending on the structure of the pricing error, i.e., whether it is related to information or not. Once we compute the total return error, $\sigma_{r}^{2}=\operatorname{Var}\left(r_{t}\right)$, we can compute the measure of market quality, i.e.,

$$
q=1-\frac{\sigma_{s}^{2}}{\sigma_{r}^{2}}=\frac{\sigma_{e}^{2}-2 a \operatorname{Cov}\left(e_{t}, e_{t-1}\right)}{\sigma_{e}^{2}+a^{2} \sigma_{e}^{2}-2 a \operatorname{Cov}\left(e_{t}, e_{t-1}\right)}
$$

It is clear that when $a=0$, the market quality is $q=1$. 


\section{References}

Alexander, G., A. Edwards, and M. Ferri (2000). "What Does NASDAQ's High Yield Bond Market Reveal About Bondholder-Stockholder Conflicts?," Financial Management 29(1), $23-29$.

Amihud, Y. (2002). "Illiquidity and Stock Returns: Cross-Section and Time-Series Effects," Journal of Financial Markets 5(1), 31-56.

Ashcraft, A., and J. Santos (2009). "Has the CDS Market Lowered the Cost of Corporate Debt?," Journal of Monetary Economics 56(4), 514-523.

Baba, N., and M. Inada (2009). "Price Discovery of Subordinated Credit Spreads for Japanese Mega-banks: Evidence from Bond and Credit Default Swap Markets," Journal of International Financial Markets, Institutions and Money 19(4), 616-632.

Bao, J., J. Pan, and J. Wang (2011). "Liquidity of Corporate Bonds," Journal of Finance $66(3), 911-946$.

Bessembinder, H., W. Maxwell, and K. Venkataraman (2006). "Market Transparency, Liquidity Externalities, and Institutional Trading Costs in Corporate Bonds," Journal of Financial Economics 82(2), 251-288.

Blanco, R., S. Brennan, and I. Marsh (2005). "An Empirical Analysis of the Dynamic Relation between Investment-Grade Bonds and Credit Default Swaps," Journal of Finance $60(5), 2255-2281$.

Boehmer, E., S. Chava, and H. Tookes (2010). "Equity Market Quality: Do CDS, Options and Bond Markets Play a Role?," available at SSRN: http://ssrn.com/abstract=1658694 or http://dx.doi.org/10.2139/ssrn.1658694.

Campbell, J., and G. Taksler (2003). "Equity Volatility and Corporate Bond Yields," Journal of Finance 58(6), 2321-2349.

Chordia, T., A. Sarkar, and A. Subrahmanyam (2011). "Liquidity Dynamics and CrossAutocorrelations," Journal of Financial and Quantitative Analysis, 46(3), 709-736.

Conrad, J. (1989). "The Price Effect of Option Introduction," Journal of Finance 44(2), 487-498.

Das, S., and P. Hanouna (2010). "Run Lengths and Liquidity," Annals of Operations Research 176(1), 127-152. 
Das, S., P. Hanouna, and A. Sarin (2009). "Accounting-based versus market-based crosssectional models of CDS spreads," Journal of Banking and Finance 33(4), 719-730.

Davies, R., and S. Kim (2009). "Using Matched Samples to Test for Differences in Trade Execution Costs," Journal of Financial Markets 12(2), 173-202.

Downing, C., S. Underwood, and Y. Xing (2009). "The Relative Informational Efficiency of Stocks and Bonds: An Intraday Analysis, Journal of Financial and Quantitative Analysis 44(5), 1081-1102.

Easley, D., M. O'Hara, and P. Srinivas (1998). "Option Volume and Stock Prices: Evidence on Where Informed Traders Trade," Journal of Finance 53(2), 431-465.

Edwards, A., L. Harris, and M. Piwowar (2007). "Corporate Bond Market Transaction Costs and Transparency," Journal of Finance 62(3), 1421-1451.

Forte, S., and J. Pena (2009). "Credit Spreads: An Empirical Analysis on the Informational Content of Stocks, Bonds, and CDS," Journal of Banking and Finance 33(11), 2013-2025.

Gebhardt, W., S. Hvidkjaer, and B. Swaminathan (2005). "Stock and Bond Market Interaction: Does Momentum Spill Over??" Journal of Financial Economics 75(3), 651-690.

Goldstein, M., E. Hotchkiss, and E. Sirri (2007). "Transparency and Liquidity: A Controlled Experiment on Corporate Bonds," Review of Financial Studies 20(2), 235-273.

Goyenko, R., C. Holden, and C. Trzcinka (2009). "Do Liquidity Measures Measure Liquidity?," Journal of Financial Economics 92(2), 153-181.

Gupta, S., and R. Sundaram (2012). "CDS Auctions and Informative Biases in CDS Recovery Rates," Working paper, NYU.

Hasbrouck, J. (1993). "Assessing the Quality of a Security Market: A New Approach to Transaction-Cost Measurement," Review of Financial Studies 6(1), 191-212.

Heckman, J. (1979). "Sample Selection Bias as a Specification Error," Econometrica 47(1), $153-161$.

Hothckiss, E., and T. Ronen (2002). "The Informational Efficiency of the Corporate Bond Market: An Intra-day Analysis," Review of Financial Studies 15(5), 1325-1354.

Hou, K., and T. Moskowitz (2005). "Market Frictions, Price Delay, and the Cross-Section of Expected Returns," Review of Financial Studies 18(3), 981-1020. 
Hull, J., M. Predescu, and A. White (2004). "The Relationship between Credit Default Swap Spreads, Bond Yields, and Credit Rating Announcements," Journal of Banking and Finance 28(11), 2789-2811.

Ismailescu, I., and B. Phillips (2011). "Savior or Sinner: Credit Default Swaps and the Market for Sovereign Debt," Working paper, University of Waterloo, Available at SSRN: http://ssrn.com/abstract=2019030 or http://dx.doi.org/10.2139/ssrn.2019030.

Kwan, S. (1996). "Firm-Specific Information and the Correlation between Individual Stocks and Bonds," Journal of Financial Economics 40(1), 63-80.

Lesmond, D., J. Ogden, and C. Trzcinka (1999). "A New Estimate of Transaction Costs," Review of Financial Studies 12(5), 1113-1141.

Long, M., M. Schinski, and D. Officer (1994). "The Impact of Option Listing on the Price Volatility and Trading Volume of Underlying OTC Stocks," Journal of Economics and Finance 18(1), 89-100.

Maxwell, W., and C. Stephens (2003). "The Wealth Effects of Repurchases on Bondholders," Journal of Finance 58(2), 895-919.

Mayhew, S., and V. Mihov (2004). "How do Exchanges Select Stocks for Option Listing?" Journal of Finance 59(1), 447-471.

Merton, R. (1974). "On the Pricing of Corporate Debt: The Risk Structure of Interest Rates," Journal of Finance 29(2), 449-470.

Newey, W., and K. West (1987). "A Simple, Positive Semi-definite, Heteroskedasticity and Autocorrelation Consistent Covariance Matrix," Econometrica 55(3), 703-708.

Norden, L., and W. Wagner (2008). "Credit Derivatives and Loan Pricing," Journal of Banking and Finance 32(12), 2560-2569.

Norden, L., and M. Weber (2009). "The Co-movement of Credit Default Swap, Bond and Stock Markets: An Empirical Analysis," European Financial Management 15(3), 529-562.

Roll, R. (1984). "A Simple Implicit Measure of the Effective Bid-Ask Spread in an Efficient Market," Journal of Finance 39(4), 1127-1139.

Ronen, T. and X. Zhou (2009). "Trade and Information in the Corporate Bond Market," Journal of Financial Markets, forthcoming.

Skinner, D. (1989). "Options Markets and Stock Return Volatility," Journal of Financial Economics 23(1), 61-78. 
Sorescu, S. (2000). "The Effect of Options on Stock Prices: 1973 to 1995," Journal of Finance $55(1), 487-514$.

Stulz, R. (2010). "Credit Default Swaps and the Credit Crisis," Journal of Economic Perspectives 24(1): 7392 .

Subrahmanyam, M., D. Tang, and S. Wang (2011). "Does the Tail Wag the Dog? The Effect of Credit Default Swaps on Credit Risk," Working paper, Stern School of Business, NYU. 
FIGURE 1: Mean Size of Bond Trades Before and After Introduction of CDS.

The upper plot shows the average size of each bond transaction (in $\$$ million) before and after the introduction of CDS for the sample of CDS issuers, and the lower plot depicts the same for a pooled control sample of CDS non-issuers. The control sample includes all bond issues by firms which meet the selection criteria outlined in Appendix A but did not issue any CDS until the end of 2009 .
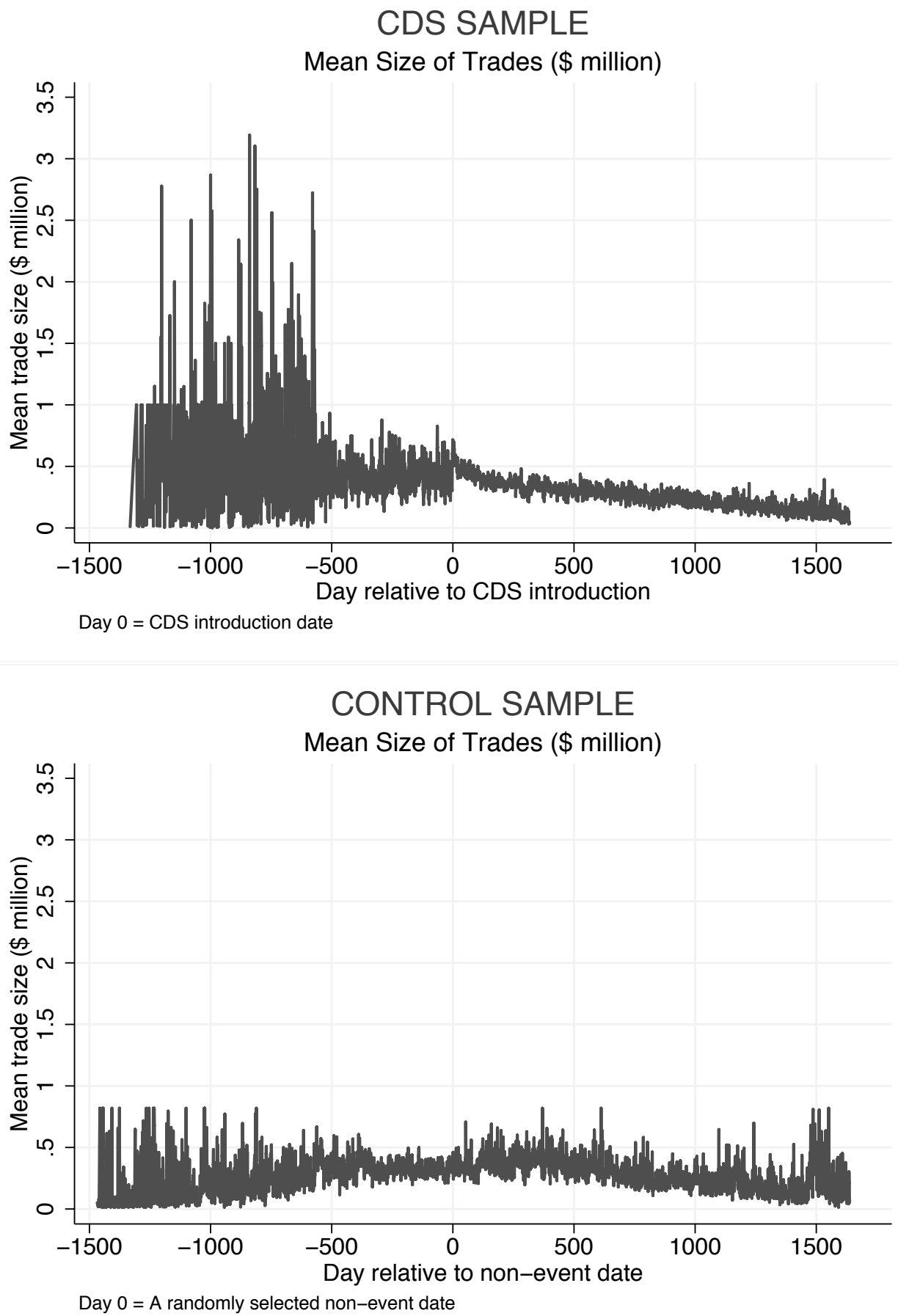
FIGURE 2: Mean Bond Turnover Before and After Introduction of CDS.

The upper plot shows the average turnover for each bond transaction (volume as $\%$ of total amount outstanding) before and after the introduction of CDS for the sample of CDS issuers, and the lower plot depicts the same for a pooled control sample of CDS non-issuers. The control sample includes all bond issues by firms which meet the selection criteria outlined in Appendix A but did not issue any CDS until the end of 2009.
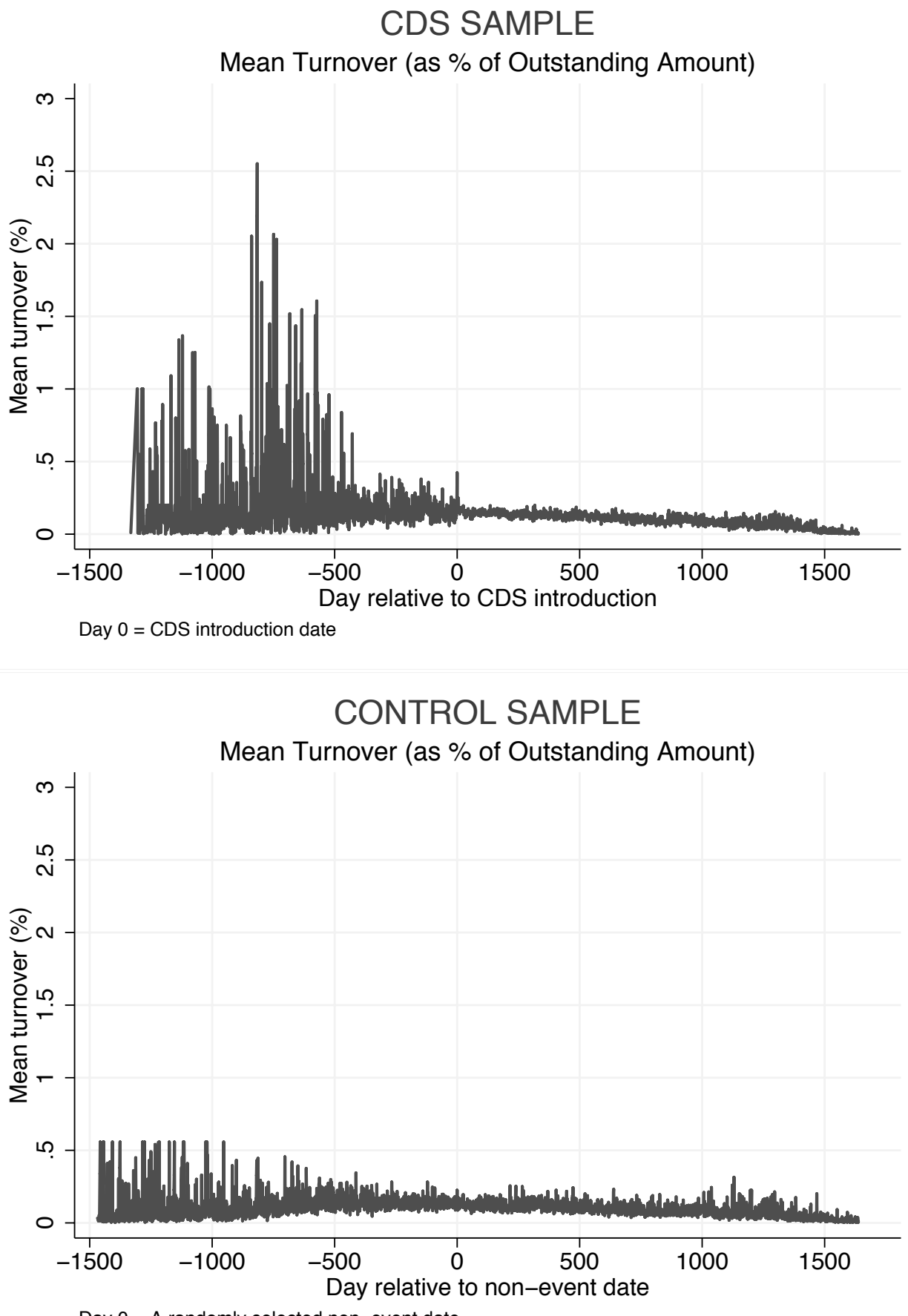

Day $0=\mathrm{A}$ randomly selected non-event date 
TABLE 1: Data Summary Statistics and Definition of Variables

\section{Panel A: Final merged data summary statistics}

- Sample period: $2002-2008$

- 1,545 bond issues by 350 issuing firms with CDS issues

- 1,365,381 time-series observations (bond issues $\times$ trading days)

- 110,934 observations before CDS introduction and 1,254,447 after

- 883.74 trading days per bond issue

- 1,545 bond issues:

- 1,352 senior issues, remaining some form of junior issues

- 1,520 fixed coupon issues, 25 zero coupon issues

- all issues non-convertible

- 662 callable, 63 putable, 820 straight bonds

- 983 Industrials, 355 Financials, 207 Utilities

- 1,365,381 time-series observations:

- \# with valid bond returns = 328,130 (24.03\%)

- \# with valid CDS spread changes = 938,944 (68.77\%)

- \# with valid stock returns = 1,294,161 (94.78\%)

- \# with valid bond returns + CDS spread changes = 258,945 (18.97\%)

- \# with valid bond returns + CDS spread changes + stock returns $=249,605(18.28 \%)$

- \# of observations prior to the introduction of CDS $=110,934(8.13 \%)$

- \# of observations subsequent to the introduction of CDS =1,254,447 (91.88\%)

- 110,934 pre-CDS time-series observations:

- \# with valid bond returns = 17,159 (15.47\%)

- \# with valid stock returns $=105,517(95.12 \%)$

- \# with valid bond returns + stock returns = 16,236 (14.64\%)

- 1,254,447 post-CDS time-series observations:

- \# with valid bond returns = 310,971 (24.79\%)

- \# with valid CDS spread changes = 938,944 (74.85\%)

- \# with valid stock returns = 1,188,644 (94.75\%)

- \# with valid bond returns + CDS spread changes $=258,945(20.64 \%)$

- \# with valid bond returns + CDS spread changes + stock returns $=249,605(19.90 \%)$ 


\section{Panel B: Definitions of variables}

- bndret: refers to bond returns (in \%) obtained as the difference of consecutive mean daily yields, i.e., as $-\left(y_{t}-y_{t-1}\right)$, where $y_{t}$ and $y_{t-1}$ are mean bond yields (in \%) on days $t$ and $t-1$ respectively.

- cdsret: refers to CDS returns (in basis points, bp) based on CDS spread changes and computed as the difference of consecutive daily yields, i.e., as $\left(y_{t}-y_{t-1}\right)$, where $y_{t}$ and $y_{t-1}$ are CDS spreads (in $\mathrm{bp}$ ) on days $t$ and $t-1$ respectively.

- stkret: refers to daily stock return (in \%).

- tryret: refers to swap return (in \%) defined as change in matching maturity consecutive swap yields, i.e., as $-\left(y_{t}-y_{t-1}\right)$, where $y_{t}$ and $y_{t-1}$ are swap yields (in \%) on days $t$ and $t-1$ respectively; yields of each bond are paired with appropriate swap yields computed based on interpolation of swap maturities to equal bond maturity.

- vixchng: refers to change in VIX measure (index value) over consecutive days.

All five variables are winsorized at the $1 \%$ level. 
TABLE 2: Classification of Bond Transactions and Descriptive Statistics of Returns

The table presents the number of bond transaction observations by year and by CDS-status of the firm at the time of the observation, and the descriptive statistics of various returns. Bond transactions of firms with CDS issues are classified into two types: (a) trades that occurred before the introduction of CDS (pre-CDS sample), and (b) trades that occurred after CDS introduction (post-CDS sample). Panel A shows the breakdown of observations by year; Panel B lists the breakdown for data sample selection criteria 1 and 2 (discussed in Section 3 and Appendix B). Panel $\mathrm{C}$ reports the descriptive statistics of various returns (defined in Table 1, Panel B) winsorized at the 1\% level. Panels D and E present the correlation coefficients between different return variables.

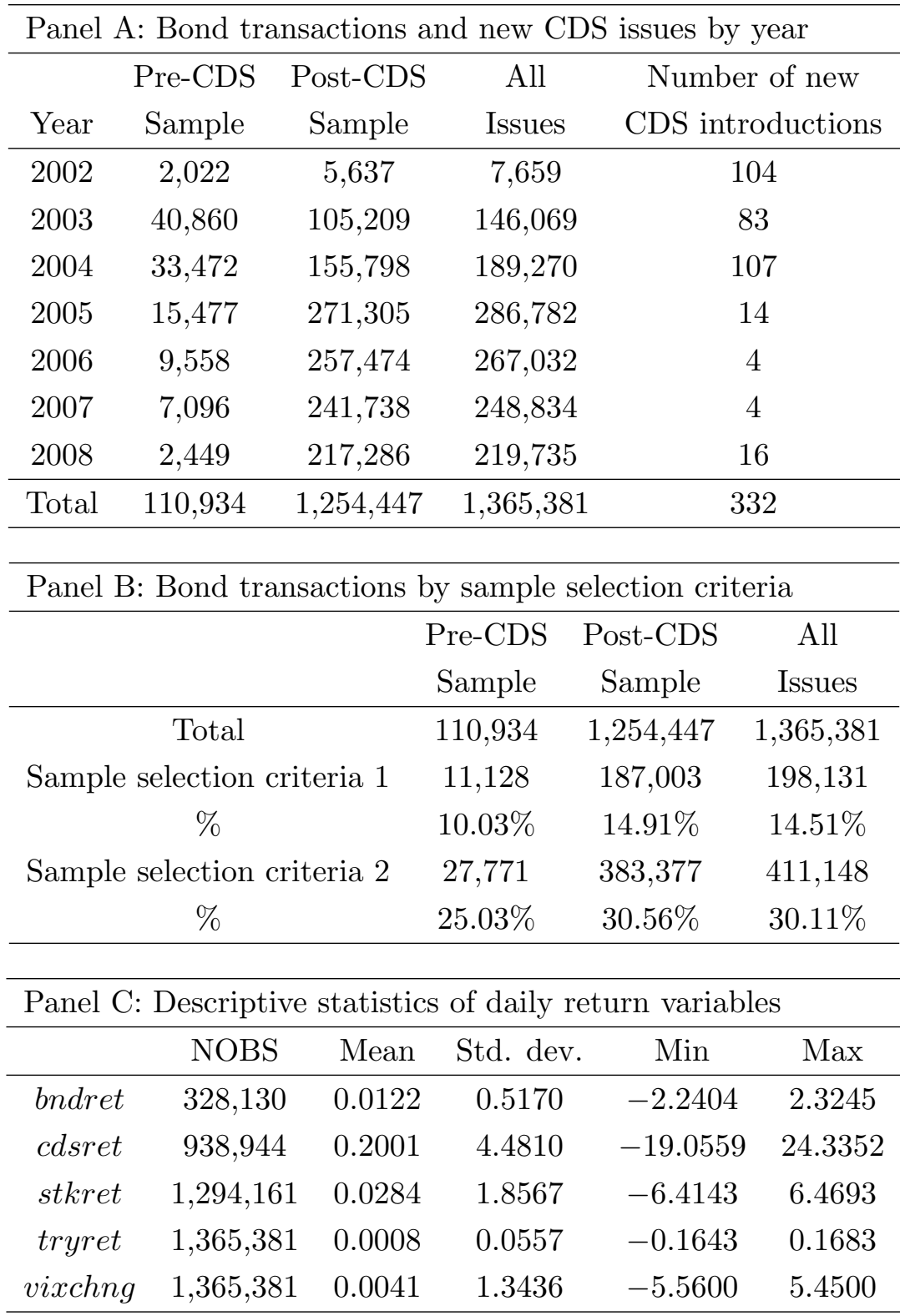




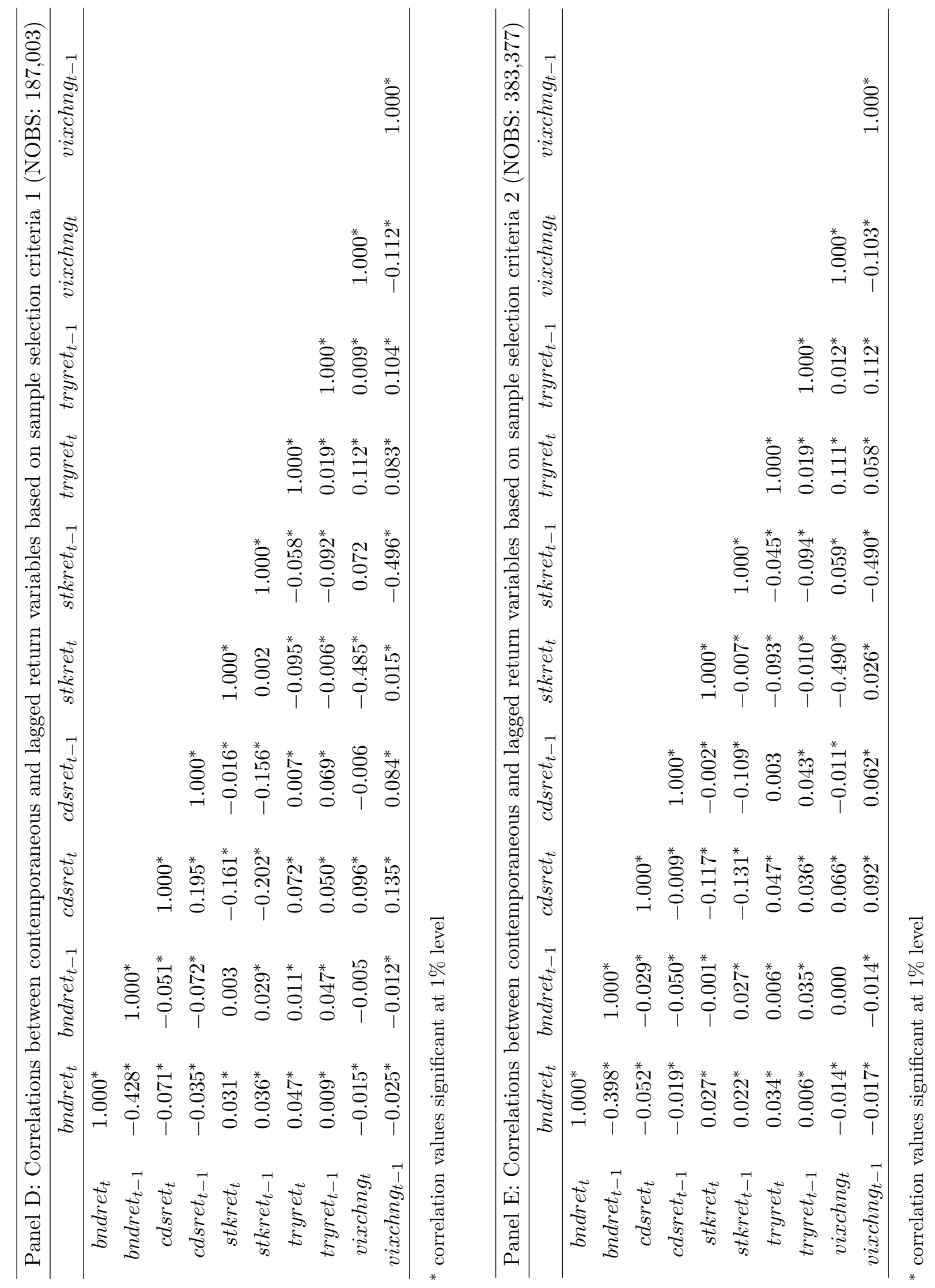


TABLE 3: Individual Bond Regressions

For individual bonds, we run separate pre-CDS and post-CDS regressions of contemporaneous bond returns on contemporaneous and lagged values of the following variables: stock returns, swap returns, changes in VIX, as well as with and without lagged bond returns (variables defined in Table 1, Panel B). The sample includes bonds with at least 30 observations in pre- as well as post-CDS periods. Panel A summarizes the results for sample selection criteria 1, and Panel B for sample selection criteria 2 (both criteria discussed in Section 3 and Appendix B).

\begin{tabular}{|c|c|c|c|c|c|}
\hline \multicolumn{6}{|c|}{ Panel A: Sample selection criteria 1} \\
\hline & \multicolumn{2}{|c|}{$D 1$} & \multirow{2}{*}{\multicolumn{3}{|c|}{$\begin{array}{c}\text { \# of bonds for which lagged } \\
\text { variables are jointly significant at }\end{array}$}} \\
\hline & \multicolumn{2}{|c|}{ Measure } & & & \\
\hline & Mean $D 1$ & Median $D 1$ & $1 \%$ level & $5 \%$ level & $10 \%$ level \\
\hline \multicolumn{6}{|c|}{ without lagged bond returns } \\
\hline Pre-CDS period & 0.33 & 0.27 & 3 & 4 & 6 \\
\hline Post-CDS period & 0.37 & 0.35 & 4 & 9 & 10 \\
\hline \multicolumn{6}{|l|}{ with lagged bond returns } \\
\hline Pre-CDS period & 0.71 & 0.79 & 33 & 38 & 38 \\
\hline Post-CDS period & 0.82 & 0.84 & 40 & 44 & 44 \\
\hline Number of bond issues & \multicolumn{2}{|c|}{45} & & & \\
\hline NOBS: Pre-CDS period & \multicolumn{2}{|c|}{6,163} & & & \\
\hline NOBS: Post-CDS period & \multicolumn{2}{|c|}{10,588} & & & \\
\hline
\end{tabular}

Number of individual bonds with at least 30 observations in pre- as well as post-CDS periods is 45 . Without lagged bond returns, 21 bonds experience decrease in value of $D 1$ measure after the introduction of CDS, and 24 bonds experience increase in value. When lagged bond returns are included, 15 bonds experience decrease in value of $D 1$ measure after the introduction of CDS, and 30 bonds experience increase in value.

\begin{tabular}{|c|c|c|c|c|c|}
\hline \multicolumn{6}{|c|}{ Panel B: Sample selection criteria 2} \\
\hline & \multicolumn{2}{|c|}{$D 1$} & \multirow{2}{*}{\multicolumn{3}{|c|}{$\begin{array}{c}\text { \# of bonds for which lagged } \\
\text { variables are jointly significant at }\end{array}$}} \\
\hline & \multicolumn{2}{|c|}{ Measure } & & & \\
\hline & Mean $D 1$ & Median $D 1$ & $1 \%$ level & $5 \%$ level & $10 \%$ level \\
\hline \multicolumn{6}{|c|}{ without lagged bond returns } \\
\hline Pre-CDS period & 0.31 & 0.25 & 4 & 12 & 19 \\
\hline Post-CDS period & 0.34 & 0.30 & 12 & 22 & 29 \\
\hline \multicolumn{6}{|l|}{ with lagged bond returns } \\
\hline Pre-CDS period & 0.67 & 0.72 & 83 & 95 & 98 \\
\hline Post-CDS period & 0.69 & 0.77 & 88 & 96 & 102 \\
\hline Number of bond issues & \multicolumn{2}{|c|}{130} & & & \\
\hline NOBS: Pre-CDS period & \multicolumn{2}{|c|}{18,290} & & & \\
\hline NOBS: Post-CDS period & \multicolumn{2}{|c|}{34,164} & & & \\
\hline
\end{tabular}

Number of individual bonds with at least 30 observations in pre- as well as post-CDS periods is 130 . Without lagged bond returns, 61 bonds experience decrease in value of $D 1$ measure after the introduction of CDS, and 69 bonds experience increase in value. When lagged bond returns are included, 59 bonds experience decrease in value of $D 1$ measure after the introduction of CDS, and 61 bonds experience increase in value. 


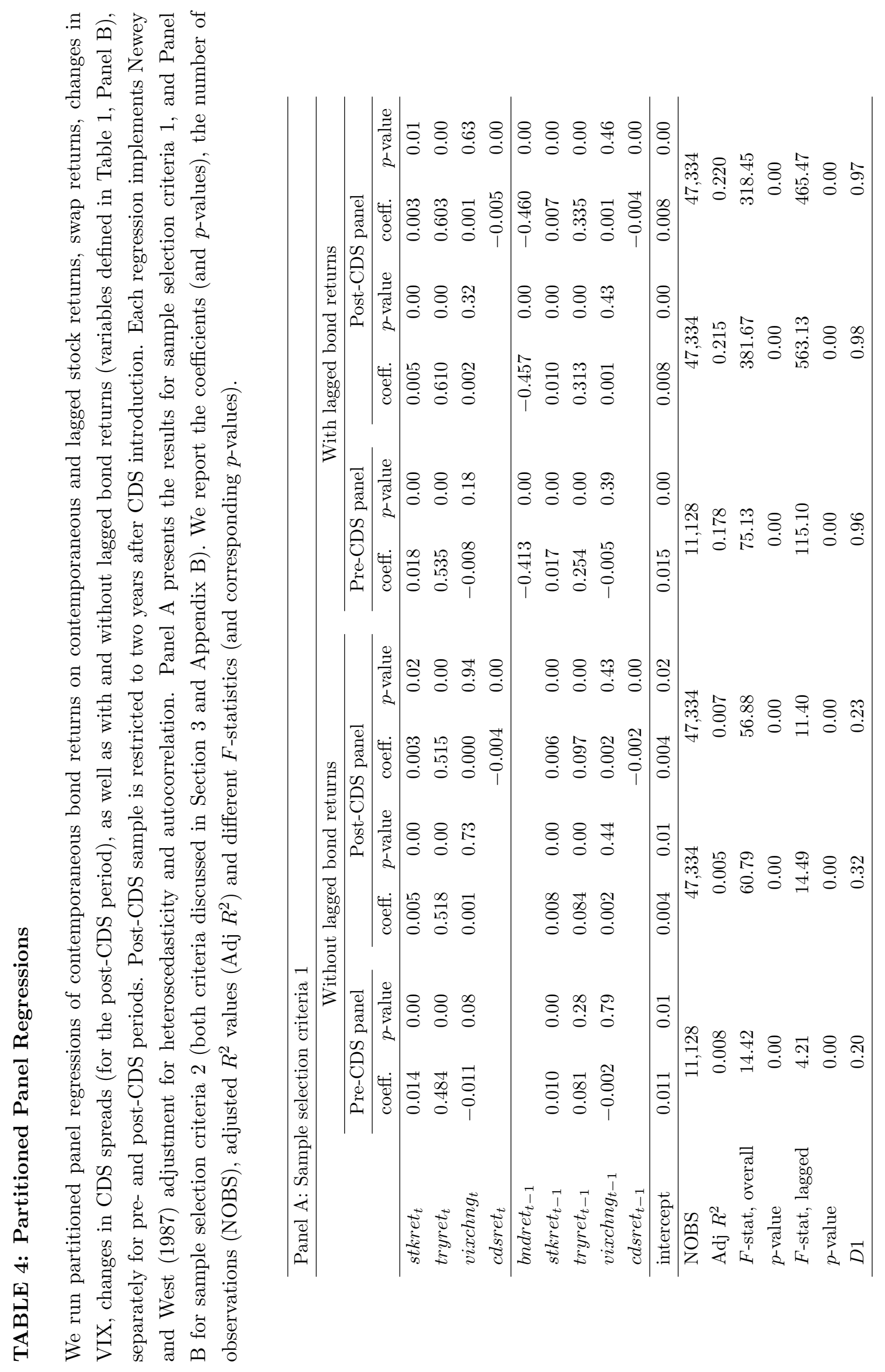




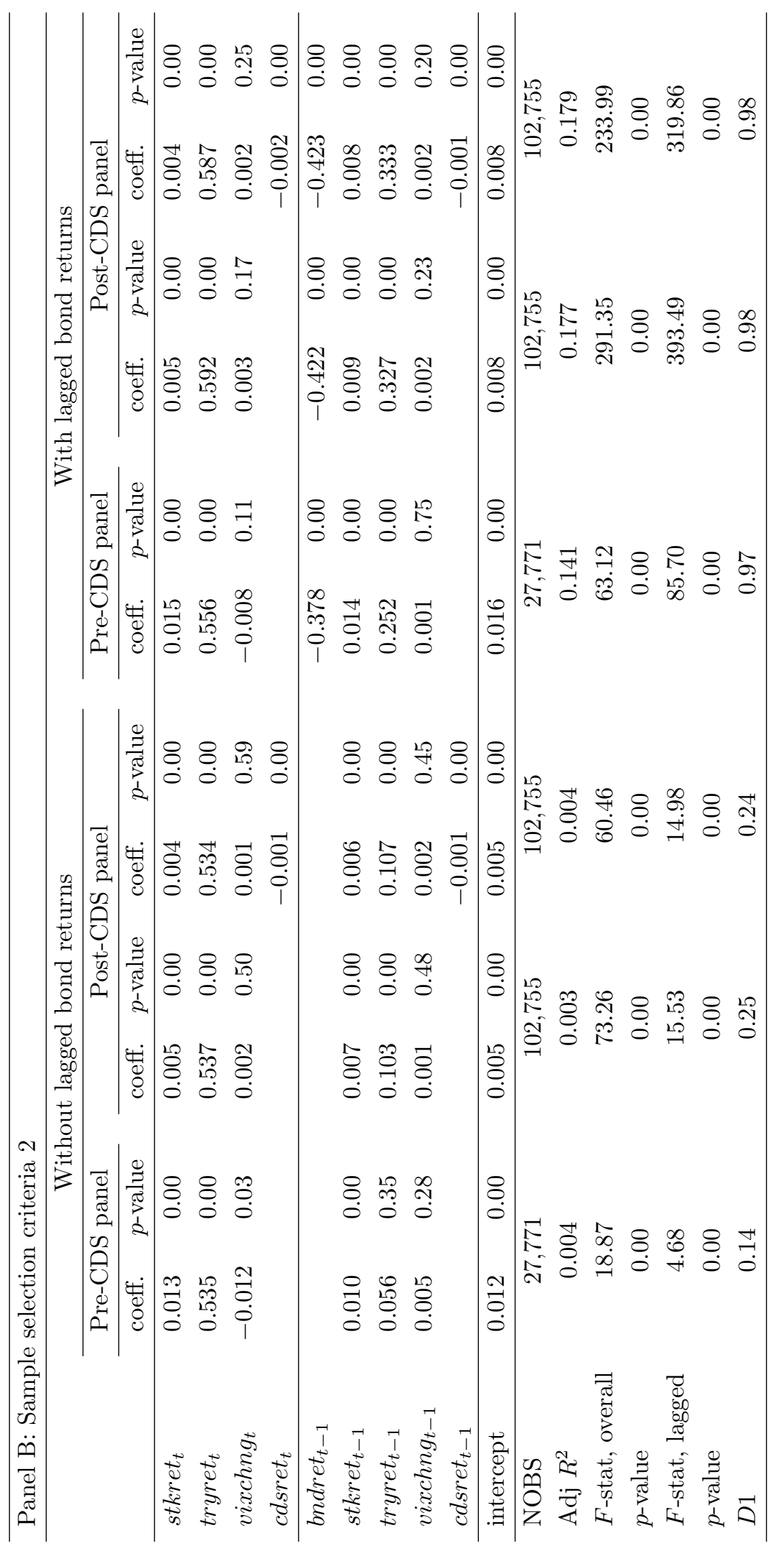


TABLE 5: Joint Panel Regressions with CDS Dummy Interaction

We run joint panel regressions of contemporaneous bond returns on contemporaneous and lagged stock returns, swap returns, changes in VIX, changes in CDS spreads (for the post-CDS period), as well as with and without lagged bond returns (variables defined in Table 1, Panel B), using both pre- and post-CDS samples simultaneously. Post-CDS sample is restricted to two years after CDS introduction. Interaction variable $C D S$ is a dummy variable that has a value of 1 for the postCDS period, and 0 for the pre-CDS period. Each regression implements Newey and West (1987) adjustment for heteroscedasticity and autocorrelation. Panel A presents the results for sample selection criteria 1, and Panel B for sample selection criteria 2 (both criteria discussed in Section 3 and Appendix B). We report the coefficients (and $p$-values), the number of observations (NOBS), adjusted $R^{2}$ values (Adj $R^{2}$ ) and different $F$-statistics (and corresponding $p$-values). Panels C, D, and $\mathrm{E}$ repeat these analyses with fixed effects for issuer firm, bond issue, and year. Panels $\mathrm{F}$ and $\mathrm{G}$ summarize the impacts of $1 \mu$ shifts and $1 \sigma$ shocks in explanatory variables. Panels $\mathrm{H}$ and I control for endogeneity: Panel $\mathrm{H}$ conducts a probit for CDS introduction (dependent variable equals 1 if CDS is introduced in a quarter, and 0 otherwise) and Panel I repeats the joint panel regressions with probability of CDS introduction as an additional variable.

\begin{tabular}{|c|c|c|c|c|}
\hline \multicolumn{5}{|c|}{ Panel A: Sample selection criteria 1} \\
\hline & \multicolumn{2}{|c|}{ Without lagged bond returns } & \multicolumn{2}{|c|}{ With lagged bond returns } \\
\hline & coefficient & $p$-value & coefficient & $p$-value \\
\hline stkret $_{t}$ & 0.015 & 0.00 & 0.018 & 0.00 \\
\hline tryret $_{t}$ & 0.489 & 0.00 & 0.540 & 0.00 \\
\hline vixchng $_{t}$ & -0.011 & 0.07 & -0.008 & 0.16 \\
\hline bndret $_{t-1}$ & & & -0.412 & 0.00 \\
\hline stkret $_{t-1}$ & 0.010 & 0.00 & 0.018 & 0.00 \\
\hline tryret $_{t-1}$ & 0.085 & 0.25 & 0.258 & 0.00 \\
\hline vixchng $_{t-1}$ & -0.002 & 0.77 & -0.005 & 0.36 \\
\hline stkret $_{t} \times C D S$ & -0.011 & 0.00 & -0.014 & 0.00 \\
\hline tryret $_{t} \times C D S$ & 0.025 & 0.76 & 0.062 & 0.41 \\
\hline vixchng $_{t} \times C D S$ & 0.012 & 0.08 & 0.009 & 0.14 \\
\hline cdsret $_{t} \times C D S$ & -0.004 & 0.00 & -0.005 & 0.00 \\
\hline bndret $_{t-1} \times C D S$ & & & -0.048 & 0.02 \\
\hline stkret $_{t-1} \times C D S$ & -0.004 & 0.21 & -0.010 & 0.00 \\
\hline tryret $_{t-1} \times C D S$ & 0.011 & 0.89 & 0.076 & 0.30 \\
\hline vixchng $_{t-1} \times C D S$ & 0.003 & 0.58 & 0.007 & 0.27 \\
\hline cdsret $_{t-1} \times C D S$ & -0.002 & 0.00 & -0.004 & 0.00 \\
\hline intercept & 0.006 & 0.00 & 0.009 & 0.00 \\
\hline NOBS & \multicolumn{2}{|c|}{58,462} & \multicolumn{2}{|c|}{58,462} \\
\hline $\operatorname{Adj} R^{2}$ & \multicolumn{2}{|c|}{0.007} & \multicolumn{2}{|c|}{0.210} \\
\hline$F$-stat, overall ( $p$-value) & \multicolumn{2}{|c|}{$38.86(0.00)$} & \multicolumn{2}{|c|}{$212.13(0.00)$} \\
\hline \multicolumn{5}{|l|}{$F$-stat, all interaction } \\
\hline variables ( $p$-value) & \multicolumn{2}{|c|}{$13.03(0.00)$} & \multicolumn{2}{|c|}{$23.57(0.00)$} \\
\hline \multicolumn{5}{|c|}{$F$-stat, only lagged interaction } \\
\hline variables ( $p$-value) & \multicolumn{2}{|c|}{$3.78(0.00)$} & \multicolumn{2}{|c|}{$16.95(0.00)$} \\
\hline
\end{tabular}




\begin{tabular}{|c|c|c|c|c|}
\hline \multicolumn{5}{|c|}{ Panel B: Sample selection criteria 2} \\
\hline & \multicolumn{2}{|c|}{ Without lagged bond returns } & \multicolumn{2}{|c|}{ With lagged bond returns } \\
\hline & coefficient & $p$-value & coefficient & $p$-value \\
\hline stkret $_{t}$ & 0.013 & 0.00 & 0.016 & 0.00 \\
\hline tryret $_{t}$ & 0.538 & 0.00 & 0.559 & 0.00 \\
\hline vixchng $_{t}$ & -0.012 & 0.03 & -0.005 & 0.10 \\
\hline bndret $_{t-1}$ & & & -0.378 & 0.00 \\
\hline stkret $_{t-1}$ & 0.010 & 0.00 & 0.015 & 0.00 \\
\hline tryret $_{t-1}$ & 0.059 & 0.33 & 0.256 & 0.00 \\
\hline vixchng $_{t-1}$ & 0.005 & 0.30 & 0.001 & 0.80 \\
\hline stkret $_{t} \times C D S$ & -0.009 & 0.01 & -0.012 & 0.00 \\
\hline tryret $_{t} \times C D S$ & -0.004 & 0.96 & 0.028 & 0.68 \\
\hline vixchng $_{t} \times C D S$ & 0.014 & 0.02 & 0.011 & 0.05 \\
\hline cdsret $_{t} \times C D S$ & -0.001 & 0.00 & -0.002 & 0.00 \\
\hline bndret $_{t-1} \times C D S$ & & & -0.055 & 0.02 \\
\hline stkret $_{t-1} \times C D S$ & -0.004 & 0.21 & -0.007 & 0.02 \\
\hline tryret $_{t-1} \times C D S$ & 0.048 & 0.46 & 0.077 & 0.22 \\
\hline vixchng $_{t-1} \times C D S$ & -0.003 & 0.53 & 0.001 & 0.78 \\
\hline cdsret $_{t-1} \times C D S$ & -0.001 & 0.00 & -0.001 & 0.00 \\
\hline intercept & 0.007 & 0.00 & 0.010 & 0.00 \\
\hline NOBS & \multicolumn{2}{|c|}{130,526} & \multicolumn{2}{|c|}{130,526} \\
\hline $\operatorname{Adj} R^{2}$ & \multicolumn{2}{|c|}{0.004} & \multicolumn{2}{|c|}{0.169} \\
\hline$F$-stat, overall ( $p$-value) & \multicolumn{2}{|c|}{$42.90(0.00)$} & \multicolumn{2}{|c|}{$159.45(0.00)$} \\
\hline \multicolumn{5}{|l|}{$F$-stat, all interaction } \\
\hline variables ( $p$-value) & \multicolumn{2}{|c|}{$7.95(0.00)$} & \multicolumn{2}{|c|}{$13.78(0.00)$} \\
\hline \multicolumn{5}{|c|}{$F$-stat, only lagged interaction } \\
\hline variables ( $p$-value) & \multicolumn{2}{|c|}{$4.64(0.00)$} & \multicolumn{2}{|c|}{$13.34(0.00)$} \\
\hline
\end{tabular}

\begin{tabular}{lccccc}
\hline Panel C: Fixed effects for bond issuer firm & & & & \\
\cline { 1 - 2 } & \multicolumn{2}{c}{ Sample selection criteria 1 } & & \multicolumn{2}{c}{ Sample selection criteria 2} \\
\cline { 2 - 3 } & $\begin{array}{c}\text { without lagged } \\
\text { bond returns }\end{array}$ & $\begin{array}{c}\text { with lagged } \\
\text { bond returns }\end{array}$ & & $\begin{array}{c}\text { without lagged } \\
\text { bond returns }\end{array}$ & $\begin{array}{c}\text { with lagged } \\
\text { bond returns }\end{array}$ \\
\hline NOBS & 58,462 & 58,462 & & 130,526 & 130,526 \\
Adj $R^{2}$ & 0.009 & 0.213 & & 0.003 & 0.170 \\
$F$-stat $(p$-value): & & & & & \\
$\quad$ overall model & $34.88(0.00)$ & $180.91(0.00)$ & & $39.23(0.00)$ & $139.09(0.00)$ \\
$\quad$ all interaction variables & $12.14(0.00)$ & $25.30(0.00)$ & & $7.27(0.00)$ & $14.23(0.00)$ \\
$\quad$ lagged interaction variables & $3.79(0.00)$ & $17.57(0.00)$ & & $4.34(0.00)$ & $13.60(0.00)$ \\
$\quad$ fixed effects & $1.26(0.00)$ & $1.76(0.00)$ & & $0.63(1.00)$ & $1.32(0.00)$ \\
degrees of freedom (fixed effects) & 259 & 259 & & 291 & 291 \\
\hline
\end{tabular}




\begin{tabular}{|c|c|c|c|c|}
\hline \multicolumn{5}{|l|}{ Panel D: Fixed effects for bond issue } \\
\hline & \multicolumn{2}{|c|}{ Sample selection criteria 1} & \multicolumn{2}{|c|}{ Sample selection criteria 2} \\
\hline & without lagged & with lagged & without lagged & with lagged \\
\hline & bond returns & bond returns & bond returns & bond returns \\
\hline NOBS & 58,462 & 58,462 & 130,526 & 130,526 \\
\hline $\operatorname{Adj} R^{2}$ & 0.009 & 0.217 & 0.001 & 0.170 \\
\hline \multicolumn{5}{|l|}{$F$-stat ( $p$-value): } \\
\hline overall model & $35.72(0.00)$ & $185.62(0.00)$ & $39.63(0.00)$ & $139.72(0.00)$ \\
\hline all interaction variables & $12.38(0.00)$ & $25.76(0.00)$ & $7.31(0.00)$ & $14.27(0.00)$ \\
\hline lagged interaction variables & $3.78(0.00)$ & $17.59(0.00)$ & $4.33(0.00)$ & $13.62(0.00)$ \\
\hline fixed effects & $1.11(0.01)$ & $1.50(0.00)$ & $0.54(1.00)$ & $1.13(0.00)$ \\
\hline degrees of freedom (fixed effects) & 922 & 922 & 1,119 & 1,119 \\
\hline \multicolumn{5}{|l|}{ Panel E: Fixed effects for year } \\
\hline & \multicolumn{2}{|c|}{ Sample selection criteria 1} & \multicolumn{2}{|c|}{ Sample selection criteria 2} \\
\hline & $\begin{array}{c}\text { without lagged } \\
\text { bond returns }\end{array}$ & $\begin{array}{l}\text { with lagged } \\
\text { bond returns }\end{array}$ & $\begin{array}{c}\text { without lagged } \\
\text { bond returns }\end{array}$ & $\begin{array}{l}\text { with lagged } \\
\text { bond returns }\end{array}$ \\
\hline NOBS & 58,462 & 58,462 & 130,526 & 130,526 \\
\hline $\operatorname{Adj} R^{2}$ & 0.007 & 0.210 & 0.004 & 0.169 \\
\hline \multicolumn{5}{|l|}{$F$-stat ( $p$-value): } \\
\hline overall model & $35.38(0.00)$ & $181.29(0.00)$ & $39.53(0.00)$ & $139.03(0.00)$ \\
\hline all interaction variables & $12.14(0.00)$ & $25.06(0.00)$ & $7.30(0.00)$ & $14.18(0.00)$ \\
\hline lagged interaction variables & $3.79(0.00)$ & $17.75(0.00)$ & $4.13(0.00)$ & $13.33(0.00)$ \\
\hline fixed effects & $0.54(0.78)$ & $0.47(0.83)$ & $0.14(0.99)$ & $0.33(0.92)$ \\
\hline degrees of freedom (fixed effects) & 6 & 6 & 6 & 6 \\
\hline
\end{tabular}

\begin{tabular}{|c|c|c|c|c|}
\hline \multicolumn{5}{|c|}{ Panel F: Impact of $1 \mu$ shift on bond returns (in basis points) } \\
\hline \multirow[b]{3}{*}{ Contribution of } & \multicolumn{2}{|c|}{ Sample selection criteria 1} & \multicolumn{2}{|c|}{ Sample selection criteria 2} \\
\hline & without lagged & with lagged & without lagged & with lagged \\
\hline & bond returns & bond returns & bond returns & bond returns \\
\hline overall model & $35 \mathrm{bp}$ & $69 \mathrm{bp}$ & $27 \mathrm{bp}$ & $51 \mathrm{bp}$ \\
\hline all interaction variables & $22 \mathrm{bp}$ & $34 \mathrm{bp}$ & $15 \mathrm{bp}$ & $21 \mathrm{bp}$ \\
\hline lagged interaction variables & $6 \mathrm{bp}$ & $13 \mathrm{bp}$ & $6 \mathrm{bp}$ & $11 \mathrm{bp}$ \\
\hline$\%$ lagged interaction & $16 \%$ & $19 \%$ & $21 \%$ & $21 \%$ \\
\hline key lagged interaction & stkret & bndret & stkret & bndret \\
\hline
\end{tabular}

\begin{tabular}{lccccc}
\hline Panel G: Impact of $1 \sigma$ shock on bond returns (in basis points) & & \\
\cline { 2 - 3 } & \multicolumn{2}{c}{ Sample selection criteria 1} & & \multicolumn{2}{c}{ Sample selection criteria 2} \\
\cline { 2 - 3 } Contribution of & $\begin{array}{c}\text { without lagged } \\
\text { bond returns }\end{array}$ & $\begin{array}{c}\text { with lagged } \\
\text { bond returns }\end{array}$ & & $\begin{array}{c}\text { without lagged } \\
\text { bond returns }\end{array}$ & $\begin{array}{c}\text { with lagged } \\
\text { bond returns }\end{array}$ \\
\hline overall model & $1783 \mathrm{bp}$ & $4527 \mathrm{bp}$ & & $1636 \mathrm{bp}$ & $4240 \mathrm{bp}$ \\
all interaction variables & $845 \mathrm{bp}$ & $1293 \mathrm{bp}$ & & $806 \mathrm{bp}$ & $1164 \mathrm{bp}$ \\
lagged interaction variables & $277 \mathrm{bp}$ & $626 \mathrm{bp}$ & & $325 \mathrm{bp}$ & $616 \mathrm{bp}$ \\
\% lagged interaction & $16 \%$ & $14 \%$ & & $20 \%$ & $15 \%$ \\
key lagged interaction & stkret & bndret & & stkret & bndret \\
\hline
\end{tabular}




\begin{tabular}{|c|c|c|c|c|}
\hline \multicolumn{5}{|c|}{ Panel H: Controlling for endogeneity, stage 1 probit } \\
\hline \multirow[b]{2}{*}{ Variable } & \multicolumn{2}{|c|}{ Results of probit } & \multicolumn{2}{|c|}{ Mean values } \\
\hline & Coefficient & $p$-value & CDS issuers & Non-issuers \\
\hline $\begin{array}{l}\text { Age } \\
\text { (years since IPO listing) }\end{array}$ & 0.003 & 0.02 & $36.92^{*}$ & $29.02^{*}$ \\
\hline $\begin{array}{l}\operatorname{Ln}(\text { Size }) \\
\quad(\text { size }=\text { total asset value })\end{array}$ & 0.121 & 0.00 & $22.77^{*}$ & $21.55^{*}$ \\
\hline Annualized 6-month equity return & -0.001 & 0.17 & 7.87 & 11.36 \\
\hline 6-month equity return volatility & -0.238 & 0.07 & $0.13^{*}$ & $0.22^{*}$ \\
\hline Amihud equity illiquidity measure & -0.011 & 0.00 & $4.58^{*}$ & $14.89^{*}$ \\
\hline $\begin{array}{l}\text { S\&P rating of long-term debt } \\
\quad \text { (numerical value; low value deno }\end{array}$ & $\begin{array}{l}\quad-0.015 \\
\text { es high qual }\end{array}$ & 0.04 & $8.15^{*}$ & $10.94^{*}$ \\
\hline Return on assets & 0.048 & 0.00 & $2.94^{*}$ & $2.61^{*}$ \\
\hline $\begin{array}{l}\text { Tobin's Q } \\
\text { (market-to-book value of assets) }\end{array}$ & -0.104 & 0.01 & 1.46 & 1.52 \\
\hline Total debt to total assets ratio & 0.670 & 0.00 & 0.32 & 0.31 \\
\hline Intercept & -2.827 & 0.00 & & \\
\hline
\end{tabular}

* differences in means significant at $1 \%$ level

\begin{tabular}{|c|c|c|c|c|}
\hline \multicolumn{5}{|c|}{ Panel I: Controlling for endogeneity, stage 2 regression } \\
\hline & \multicolumn{2}{|c|}{ Sample selection criteria 1} & \multicolumn{2}{|c|}{ Sample selection criteria 2} \\
\hline & without lagged & with lagged & without lagged & with lagged \\
\hline & bond returns & bond returns & bond returns & bond returns \\
\hline NOBS & 58,426 & 58,426 & 130,362 & 130,362 \\
\hline Adj $R^{2}$ & 0.007 & 0.210 & 0.004 & 0.169 \\
\hline \multicolumn{5}{|l|}{ Probability of CDS introduction: } \\
\hline coefficient & -0.008 & -0.012 & -0.009 & -0.012 \\
\hline$p$-value & 0.08 & 0.02 & 0.01 & 0.00 \\
\hline \multicolumn{5}{|l|}{$F$-stat ( $p$-value): } \\
\hline overall model & $36.51(0.00)$ & $199.74(0.00)$ & $40.51(0.00)$ & $150.35(0.00)$ \\
\hline all interaction variables & $12.98(0.00)$ & $23.52(0.00)$ & $7.88(0.00)$ & $13.68(0.00)$ \\
\hline lagged interaction variables & $3.76(0.00)$ & $16.90(0.00)$ & $4.84(0.00)$ & $13.58(0.00)$ \\
\hline
\end{tabular}


TABLE 6: Full Panel Difference-in-Differences Regressions

We augment our sample of pre- and post-CDS bond transactions for CDS issuers with control samples of bond transactions by CDS non-issuers (firms with no CDS introduction). Control samples are constructed in two ways (detailed in Section 3): (a) matched control sample that consists of transactions of the closest matching bond (in terms of bond size, rating, and maturity, and firm size) of a CDS non-issuer for each bond of CDS issuers; and (b) pooled control sample that aggregates all bond transactions of issuing firms which meet the selection criteria outlined in Appendix A but did not issue any CDS until the end of 2009. Post-CDS sample is restricted to two years after CDS introduction. For the combined (event plus control) sample of all observations, we run the following regression with Newey and West (1987) adjustment for heteroscedasticity and autocorrelation:

$$
\begin{aligned}
\text { bndret }_{i t}= & \alpha_{i}+\beta_{1} C V_{i}+\beta_{2} L V_{i}+\beta_{3} C D S_{i t} * C V_{i}+\beta_{4} C D S_{i, t-1} * L V_{i} \\
& +\beta_{5} E_{i} * C V_{i}+\beta_{6} E_{i} * L V_{i}+\beta_{7} E_{i} * C D S_{i t} * C V_{i}+\beta_{8} E_{i} * C D S_{i, t-1} * L V_{i}
\end{aligned}
$$

where

$$
\begin{aligned}
& C V_{i} \equiv\left\{\text { stkret }_{i t}, \text { tryret }_{i t}, \text { vixchng }_{i t}, \text { cdsret }_{i t}\right\} \\
& L V_{i} \equiv\left\{\text { bndret }_{i, t-1}, \text { stkret }_{i, t-1}, \text { tryret }_{i, t-1}, \text { vixchng }_{i, t-1}, \text { cdsret }_{i, t-1}\right\} \\
& C D S_{i t}=1 \text { if post-CDS period and } 0 \text { if pre-CDS period } \\
& E_{i}=1 \text { for event sample of CDS-issuers and } 0 \text { for control sample of non-issuers }
\end{aligned}
$$

$C V_{i}$ and $L V_{i}$ denote contemporaneous and lagged (explanatory) variables respectively (variables defined in Table 1, Panel B). Classification of transactions into pre- and post-CDS periods $\left(C D S_{i t}\right.$ $=0$ vs. 1) is based on the actual CDS introduction date for CDS issuers and matched control

\begin{tabular}{|c|c|c|c|c|}
\hline \multicolumn{5}{|c|}{ Panel A: Sample selection criteria 1} \\
\hline \multirow[b]{3}{*}{$\begin{array}{l}\text { Regression } \\
\text { coefficients }\end{array}$} & \multicolumn{4}{|c|}{$F$-statistics ( $p$-value $)$} \\
\hline & \multicolumn{2}{|c|}{ Matched control sample } & \multicolumn{2}{|c|}{ Pooled control sample } \\
\hline & $\begin{array}{c}\text { Without lagged } \\
\text { bond returns }\end{array}$ & $\begin{array}{l}\text { With lagged } \\
\text { bond returns }\end{array}$ & $\begin{array}{c}\text { Without lagged } \\
\text { bond returns }\end{array}$ & $\begin{array}{l}\text { With lagged } \\
\text { bond returns }\end{array}$ \\
\hline [Full model] & $94.72(0.00)$ & $292.52(0.00)$ & $35.08(0.00)$ & $149.79(0.00)$ \\
\hline$\beta_{1}+\beta_{2}$ & $59.63(0.00)$ & $237.67(0.00)$ & $42.16(0.00)$ & $97.95(0.00)$ \\
\hline$\beta_{2}$ & $36.24(0.00)$ & $336.53(0.00)$ & $38.90(0.00)$ & $126.94(0.00)$ \\
\hline$\beta_{3}+\beta_{4}$ & $11.77(0.00)$ & $14.01(0.00)$ & $1.59(0.14)$ & $1.40(0.20)$ \\
\hline$\beta_{4}$ & $2.18(0.09)$ & $9.76(0.00)$ & $2.48(0.06)$ & $1.22(0.30)$ \\
\hline$\beta_{5}+\beta_{6}$ & $6.50(0.00)$ & $7.49(0.00)$ & $12.48(0.00)$ & $16.16(0.00)$ \\
\hline$\beta_{6}$ & $7.08(0.00)$ & $11.33(0.00)$ & $12.71(0.00)$ & $21.42(0.00)$ \\
\hline$\beta_{7}+\beta_{8}$ & $16.00(0.00)$ & $25.77(0.00)$ & $11.72(0.00)$ & $20.01(0.00)$ \\
\hline$\beta_{8}$ & $4.23(0.00)$ & $17.14(0.00)$ & $4.17(0.00)$ & $13.36(0.00)$ \\
\hline
\end{tabular}
sample of CDS non-issuers, and on an arbitrarily selected date (derived from uniform random distribution) for pooled control sample of CDS non-issuers. Panel A presents the results for sample selection criteria 1, and Panel B for sample selection criteria 2 (both criteria discussed in Section 3 and Appendix B). We report the $F$-statistics (and associated $p$-values) for the overall model and those corresponding to the joint significance of various sets of explanatory variables. 


\begin{tabular}{lccccc}
\hline \multicolumn{3}{l}{ Panel B: Sample selection criteria 2} \\
\cline { 2 - 3 } & \multicolumn{4}{c}{$F$-statistics } & $(p$-value $)$ \\
\cline { 2 - 3 } Regression & \multicolumn{2}{c}{ Matched control sample } & & Pooled control sample \\
\cline { 2 - 3 } \cline { 5 - 6 } coefficients & Without lagged & With lagged & & Without lagged & With lagged \\
bondurns & bond returns & & bond returns & bond returns \\
\hline Full model $]$ & $121.08(0.00)$ & $353.38(0.00)$ & & $36.80(0.00)$ & $149.09(0.00)$ \\
$\beta_{1}+\beta_{2}$ & $99.40(0.00)$ & $364.57(0.00)$ & & $51.42(0.00)$ & $91.38(0.00)$ \\
$\beta_{2}$ & $36.13(0.00)$ & $509.60(0.00)$ & & $48.99(0.00)$ & $111.52(0.00)$ \\
$\beta_{3}+\beta_{4}$ & $3.01(0.01)$ & $3.93(0.00)$ & & $1.63(0.14)$ & $2.28(0.03)$ \\
$\beta_{4}$ & $2.24(0.08)$ & $2.72(0.03)$ & & $3.01(0.03)$ & $3.65(0.01)$ \\
$\beta_{5}+\beta_{6}$ & $3.88(0.00)$ & $4.21(0.00)$ & & $15.28(0.00)$ & $19.76(0.00)$ \\
$\beta_{6}$ & $6.35(0.00)$ & $7.08(0.00)$ & & $15.52(0.00)$ & $26.62(0.00)$ \\
$\beta_{7}+\beta_{8}$ & $6.60(0.00)$ & $11.03(0.00)$ & & $11.47(0.00)$ & $19.77(0.00)$ \\
$\beta_{8}$ & $5.00(0.00)$ & $11.32(0.00)$ & & $4.65(0.00)$ & $13.89(0.00)$ \\
\hline
\end{tabular}




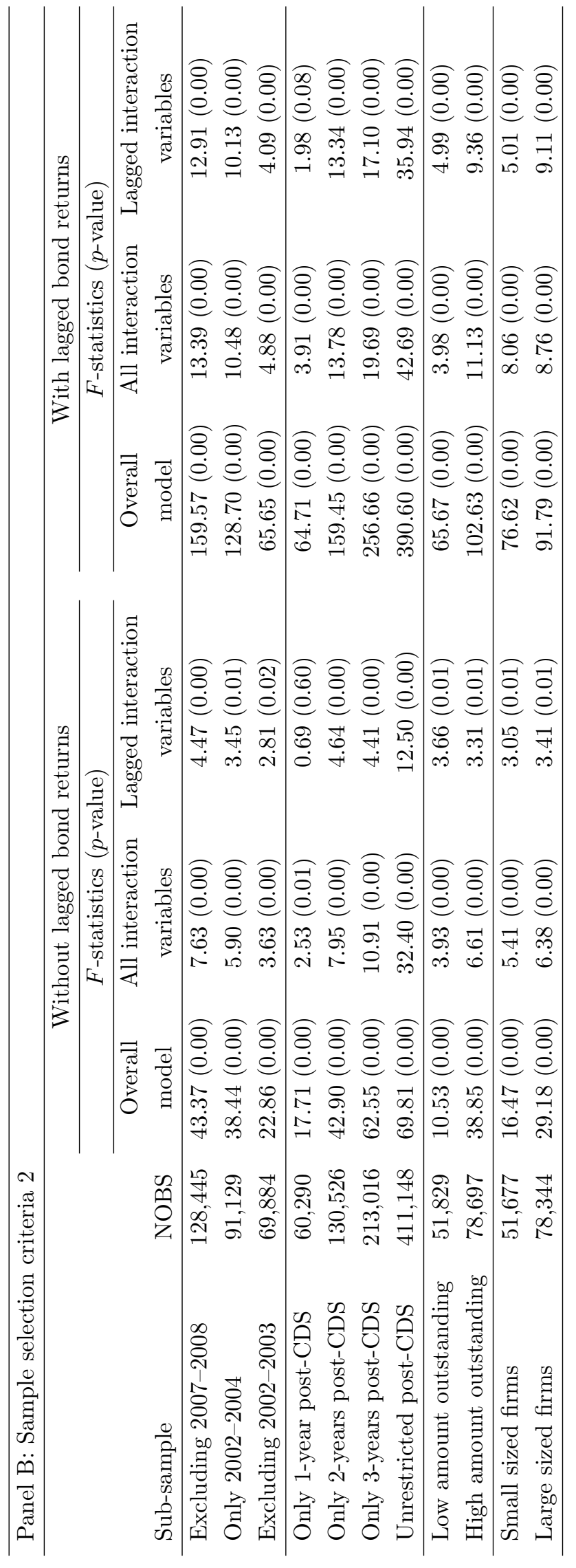




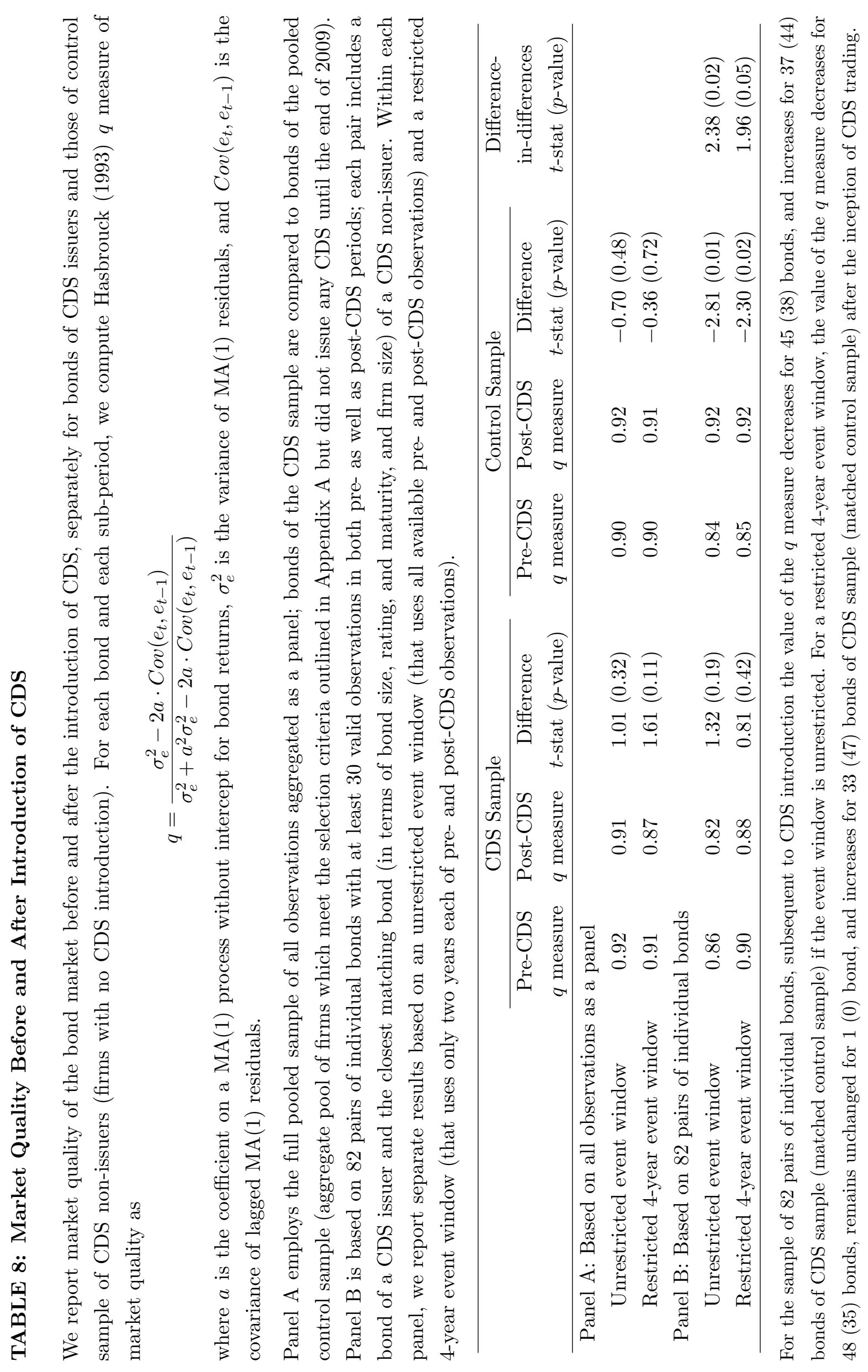




\section{TABLE 9: Bond Liquidity Attributes Before and After Introduction of CDS}

We report the values of various bond liquidity and price impact metrics before and after the introduction of CDS, separately for bonds of CDS issuers and control sample bonds of CDS nonissuers. Panel A employs the full pooled sample of all observations aggregated as a panel; all observations for CDS issuers are augmented with the pooled control sample which consists of all bond transactions for firms which meet the selection criteria outlined in Appendix A but did not issue any CDS until the end of 2009. Panel B is based on 82 pairs of individual bonds (257 pairs for the relaxed LOT measure) with at least 30 valid observations in both pre- as well as post-CDS periods; each pair includes a bond of a CDS issuer and the closest matching bond (in terms of bond size, rating, and maturity, and firm size) of a CDS non-issuer. Tests for difference between means and medians are based on $t$-test and Wilcoxon (Mann-Whitney) rank-sum test respectively. We compute the following liquidity attributes; each measure is computed over a four-year window using two years each of pre- and post-CDS observations:

1. \# of trades

2. Trading volume: in $\$$ million

3. Turnover $=$ trading volume as a percentage of outstanding amount

4. LOT zeros measure: based on Das and Hanouna (2010) adaptation of Lesmond, Ogden and Trzcinka (1999) measure; computed as frequency of zero return and zero volume trading days as a fraction of total number of trading days

5. Zeros impact illiquidity measure: based on Goyenko, Holden and Trzcinka (2009)

$$
\text { Zeros Impact }{ }_{i}=\frac{10^{6} \times(\text { number of zero return plus zero volume trading days })}{\sum_{t=1}^{D A Y S_{i}} \$ V O L_{i t}}
$$

6. Amihud illiquidity measure: based on Amihud (2002)

$$
\text { Amihud Illiquidity }_{i}=\frac{1}{D A Y S_{i}} \sum_{t=1}^{D A Y S_{i}} \frac{\mid \text { bndret }_{i t} \mid}{\$ V O L_{i t}} \times 10^{6}
$$

7. Amivest liquidity measure: based on Goyenko, Holden and Trzcinka (2009)

$$
\text { Amivest Liquidity }_{i}=\frac{1}{D A Y S_{i}} \sum_{t=1}^{D A Y S_{i}} \frac{\$ V O L_{i t}}{\mid \text { bndret }_{i t} \mid} \times 10^{-6}
$$

8. Roll spread illiquidity estimator: based on Roll (1984)

$$
\text { Roll Estimator }_{i}=\left\{\begin{array}{cl}
\sqrt{-\left(\operatorname{Cov}\left(\Delta P_{i t}, \Delta P_{i, t-1}\right)\right)} & \text { if } \operatorname{Cov}\left(\Delta P_{i t}, \Delta P_{i, t-1}\right)<0 \\
0 & \text { otherwise }
\end{array}\right.
$$

9. Roll impact illiquidity measure: based on Goyenko, Holden and Trzcinka (2009)

$$
\text { Roll Impact }_{i}=\frac{10^{6} \times \text { Roll Estimator }_{i}}{\left(\sum_{t=1}^{D A Y S_{i}} \$ V O L_{i t}\right) / D A Y S_{i}}
$$

10. Bao-Pan-Wang illiquidity gamma: based on Bao, Pan and Wang (2011)

$$
\gamma_{i}=-\operatorname{Cov}\left(\Delta P_{i t}, \Delta P_{i, t-1}\right)
$$

bndret $_{i t}$ is the $i$ th bond's return on day $t, P_{i t}$ is the daily mean bond price, $\$ V O L_{i t}$ is the total daily trading volume in dollars, and $D A Y S_{i}$ is the total number of trading days in the entire pre- or post-CDS period. 


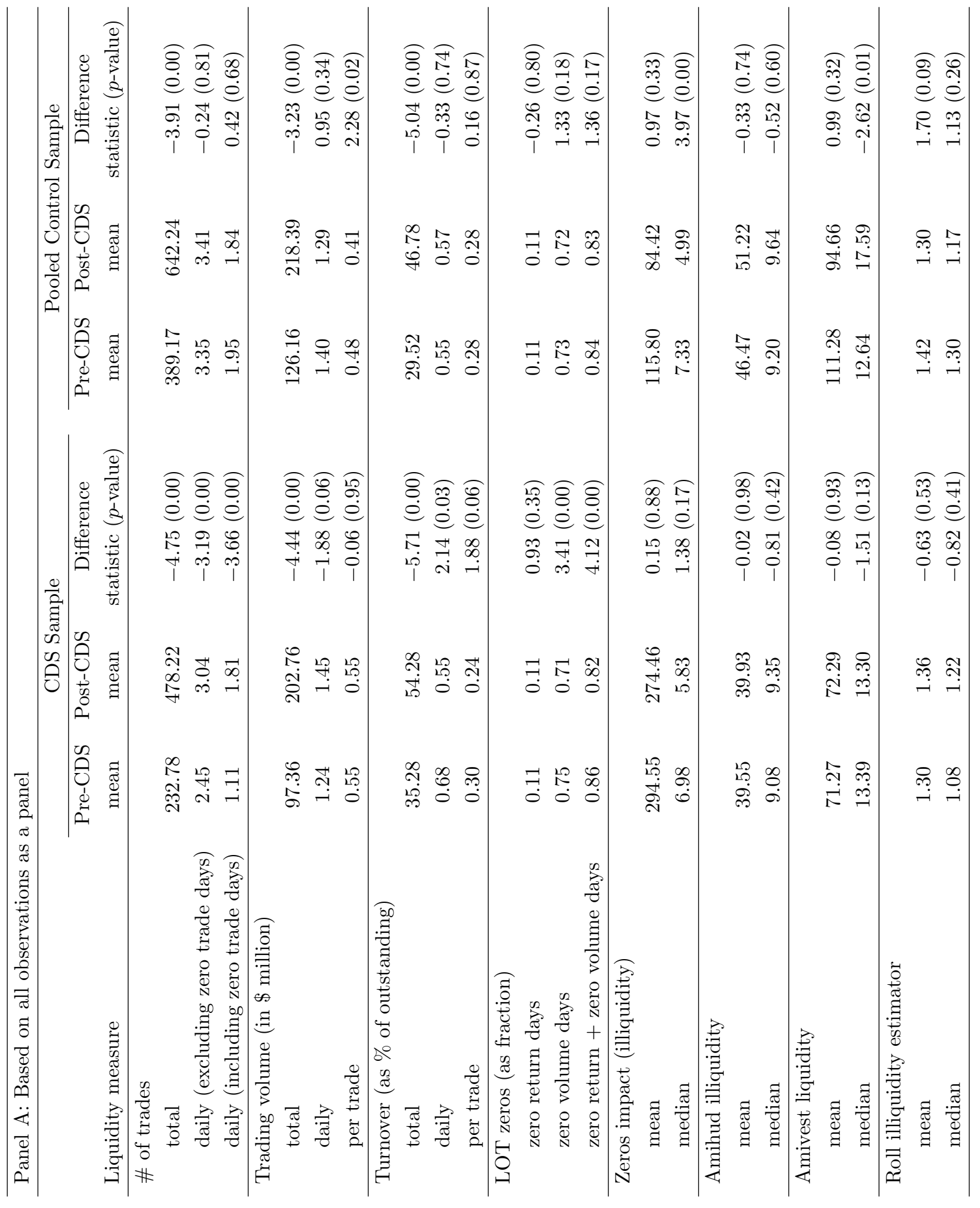



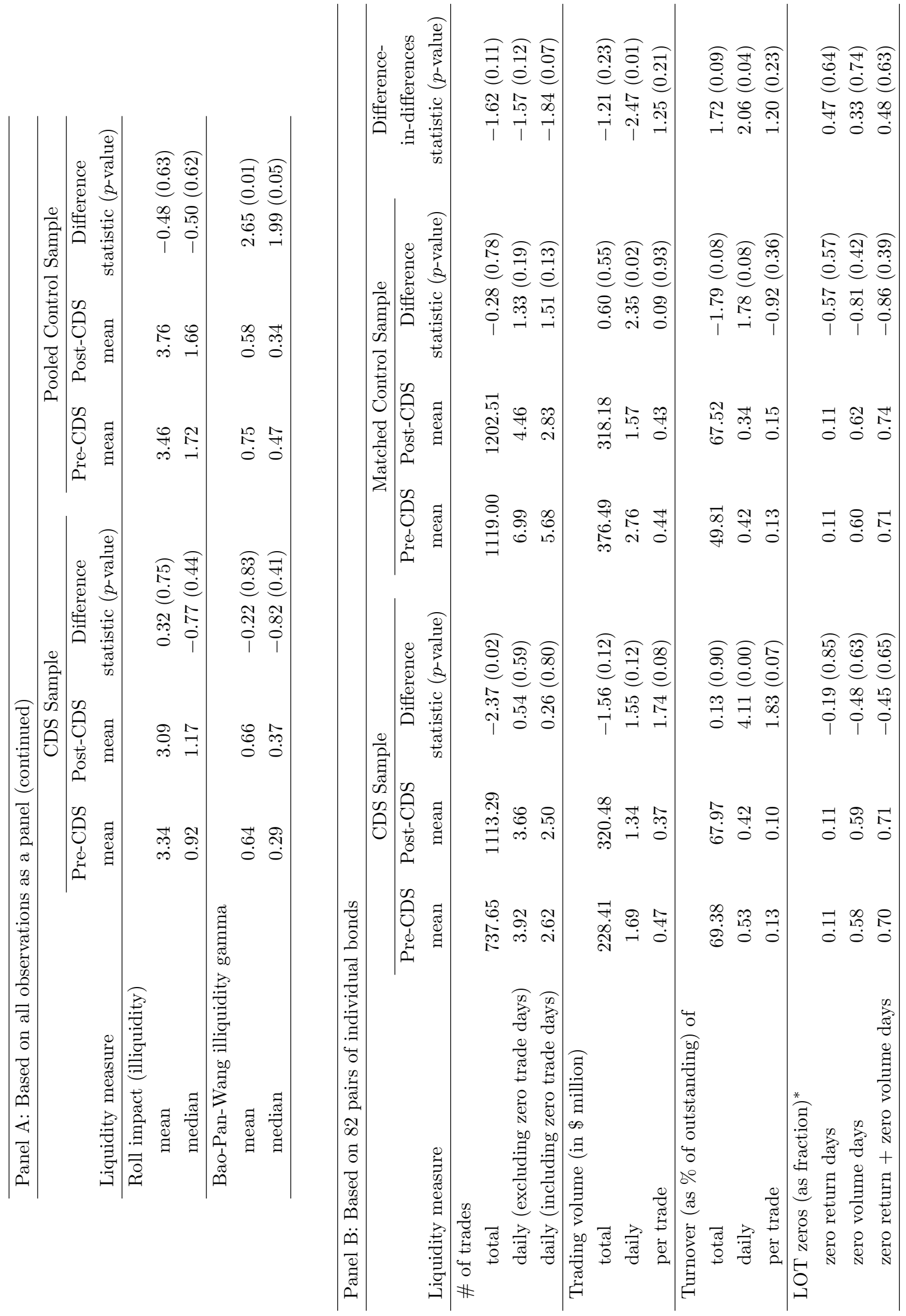


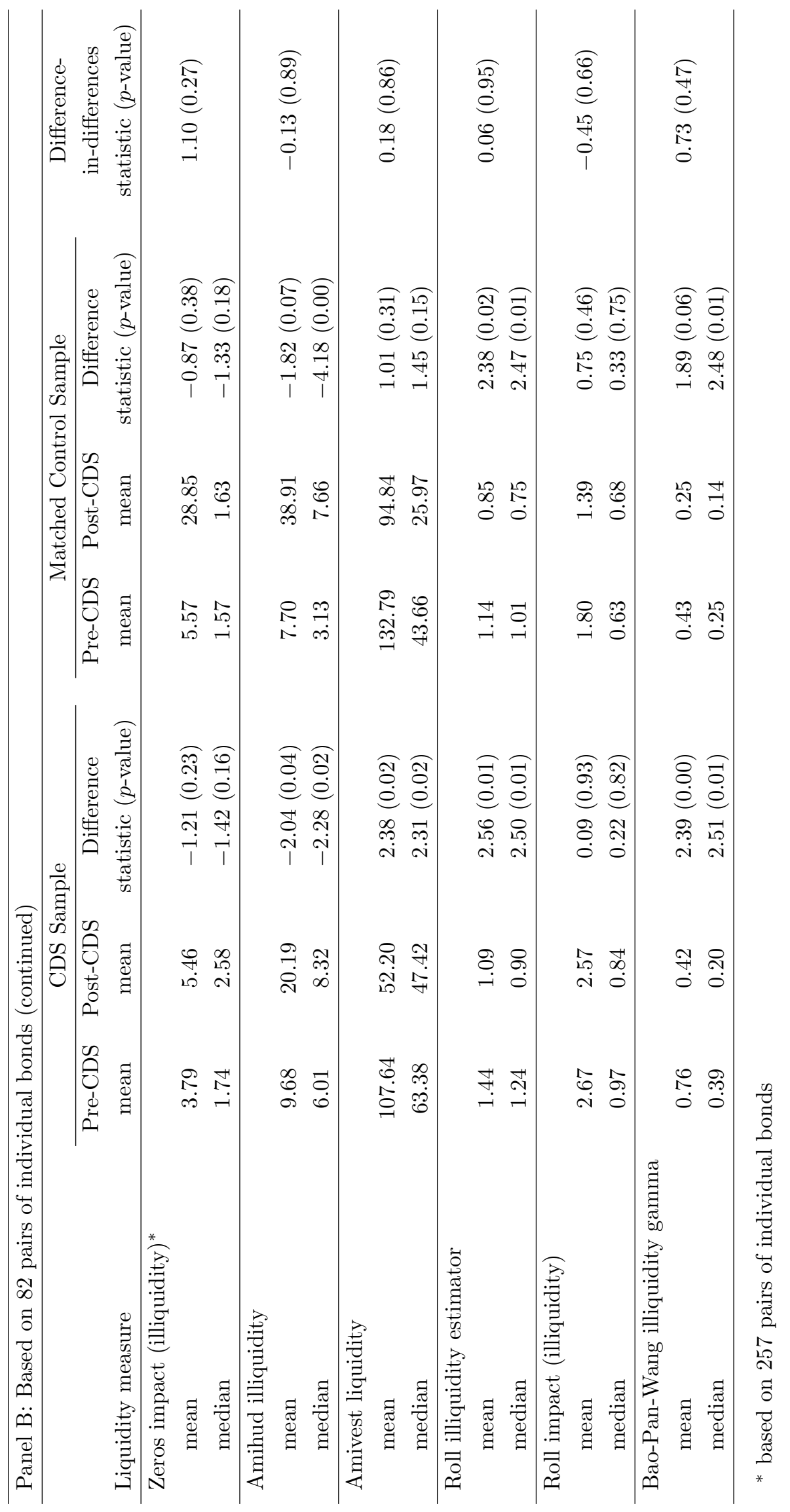




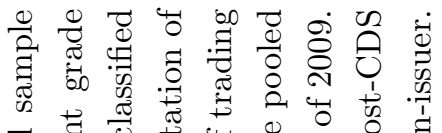

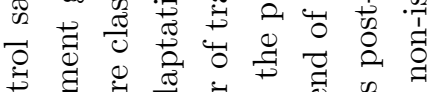
旁 \%

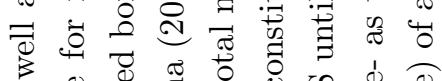

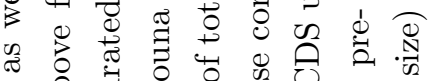
g

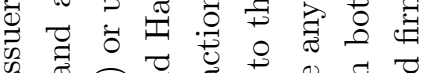

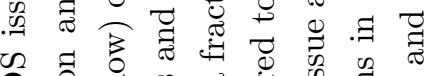

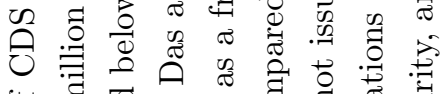
क

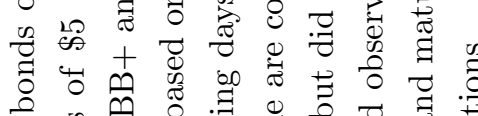

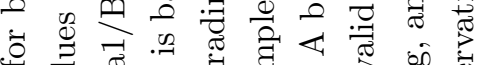

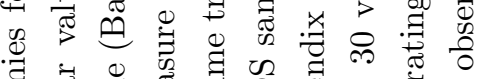

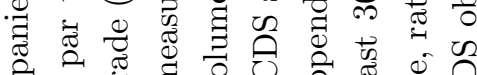

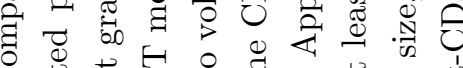

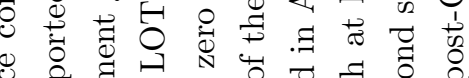
है

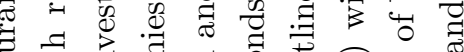

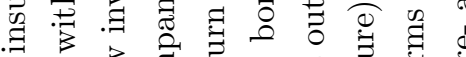
, की 8

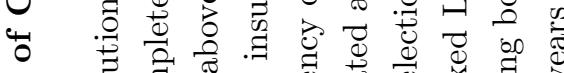

을

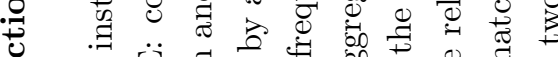

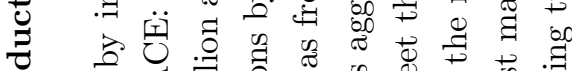

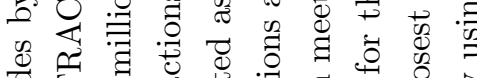

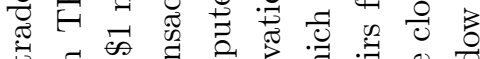

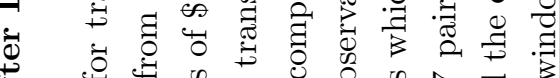

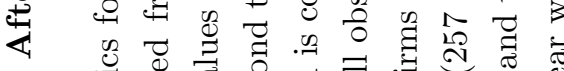

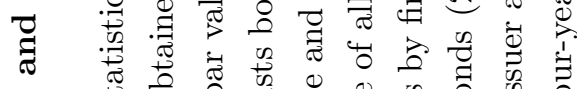

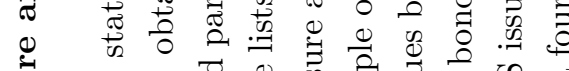

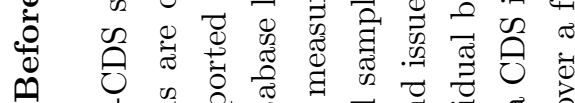
tris

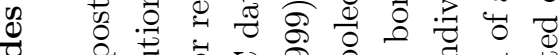

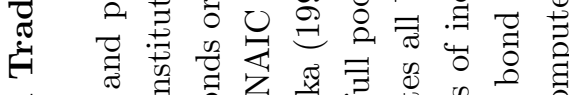

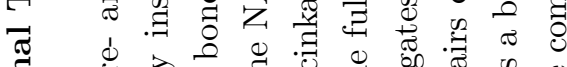

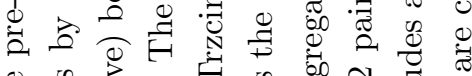

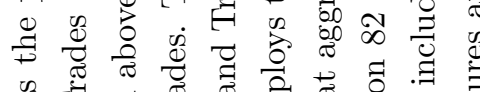

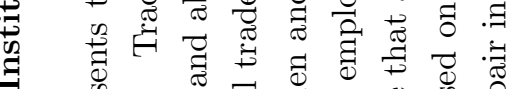

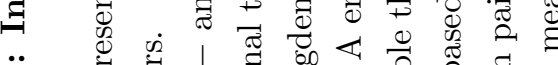

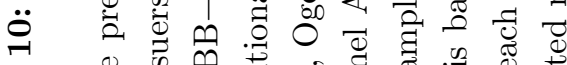

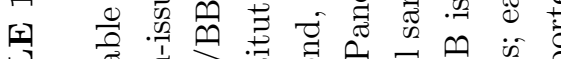

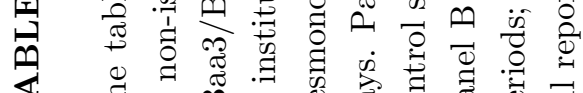

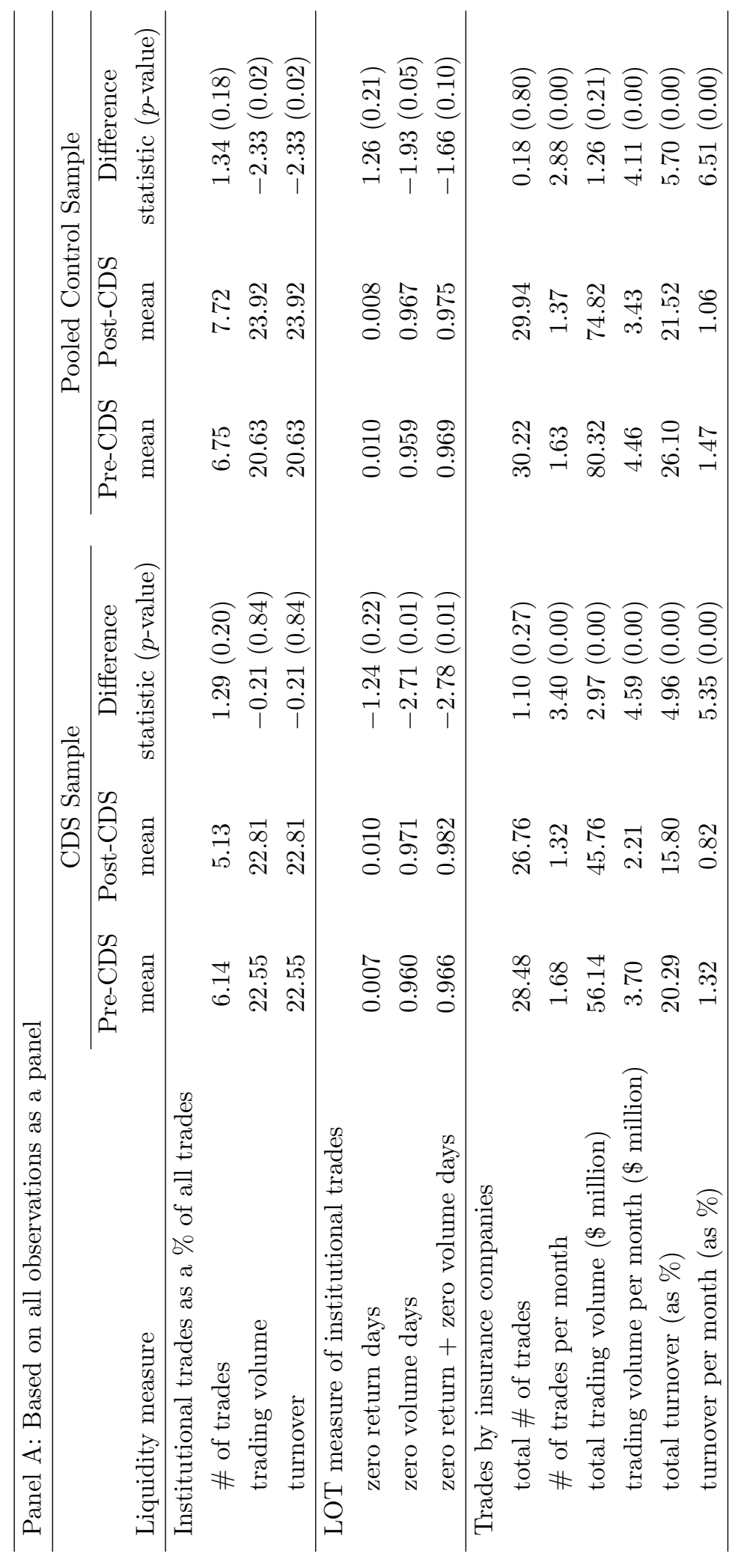

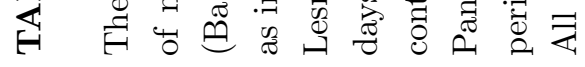




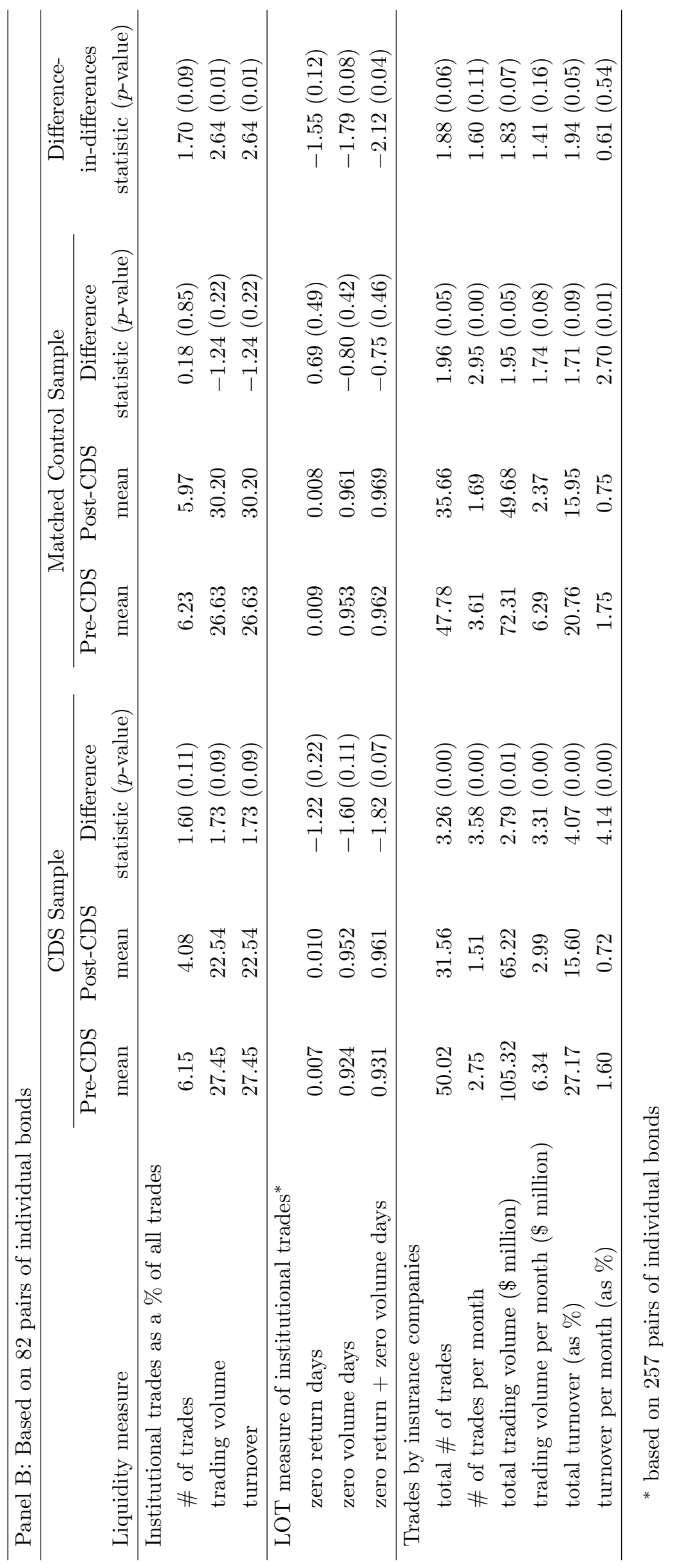

